\title{
LA FRONTERA SUR DE EUROPA: TENDENCIAS EVOLUTIVAS (1)
}

Juan J. Linz

El sur de Europa o el Mediterráneo Norte, especialmente la Península Ibérica, ha ocupado una posición marginal en el desarrollo de la Nueva Europa. El hecho de que España y Portugal, e intermitentemente Grecia, fueran regímenes autoritarios y de que los países ibéricos no participaran en la Segunda Guerra Mundial al lado de los Vencedores, además de otros factores históricos, económicos y sociales, explican esa marginalidad y esa marginación. Actualmente en Portugal, Grecia y España, han sido restablecidas las instituciones democráticas $\mathrm{y}$ están luchando por su consolidación, mientras

1 Este articulo fue escrito mientras el autor sostenía un German Marshall Fund de la United States Fellowship. Me beneficié de las discusiones llevadas a cabo en la Asociación Internacional de Ciencia Política. en la Mesa Redonda de la Conferencia sobre el Mediterráneo Europeo, de mayo de 1978 en Atenas, y de la asistencia a la misma de Rocío de Terán.

Las referencias bibliográficas no deben ser interpretadas como una guía para el estudio de la historia, de la política, de la economía y de la sociedad de estos países. Se pueden encontrar referencias bibliográficas en: Revolution in Portugal: 1974-1976. A Bibliography, en Essays in Portuguese Studies, vol. 2 (International Conference Group on Modern Portugal, University of New Hampshire, Durham, N. H., 1978): Modern Greek Society, A Social Science Newsletter (New Hampton, N. Y.); Newsletter, Conference Group on Italian Politics; Portuguese Studies Mewsletter (Durham, N. H.), y Sociedad de Estudios Históricos Españoles y Portugueses, Bulletin.

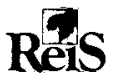


que en Italia, el cuarto país mediterráneo, después de treinta años de democracia, ésta está sobreviviendo sin gobierno. La esperanza y el temor por la democracia política en la Europa mediterránea han vuelto la atención del mundo a esta zona estratégica.

\section{Europa del Sur: sociedades cambiantes}

Para proveer un marco adecuado a nuestro análisis sobre las políticas mediterráneas, nos ha parecido útil sacar a la luz algunas características demográficas, económicas y sociales de los cuatro países principales de la zona ${ }^{2}$. Lo primero que debe ser resaltado son sus poblaciones, que tienen un gran peso con respecto a la población europea total, dejando fuera a la Unión Soviética, siendo la italiana la cuarta más grande y (cuando se tiene en cuenta a la Turquía extra-europea) la española la séptima, inmediatamente después de la francesa. Incluso el pequeño Portugal y Grecia tienen una población mayor que la de países como Suecia, Austria y Suiza, y cada uno tiene casi el doble de población que Dinamarca, Finlandia o Noruega. La población de los cuatro países sumaba en 1975 casi los 110 millones de habitantes, mientras que los países del Benelux, Suecia, Austria y Suiza -la mayor de las democracias europeas menores - solamente tenían 45,9 millones de habitantes. El PNB de Italia, España,. Portugal y Grecia fue en 1975, a los precios de mercado en dólares USA, de 290.110 millones, con una media per cápita de 2.641 dólares. El PNB total de los países europeos menores, arriba mencionados, fue casi el mismo, de 299.490 millones de dólares, pero la diferencia de población se traduce en que la renta per cápita fue en los últimos de 6.776 dólares. Europa del Sur es, por tanto, el hogar de un gran número de personas —uno de cada cinco europeos fuera de la Unión Soviética y uno de cada cuatro en la Europa no comunista--, pero también es una zona relativamente subdesarrollada económicamente si se compara con otras parte del continente.

2 Las fuentes básicas de las que se han tomado los datos referidos en el texto y que permiten establecer comparaciones sistemáticas son: World Bank Atlas, Population, per capita product and Growth Rates (Washington, D. C.: World Bank, 1977), p. 18. Bartholomew Scribner, Atlas of Europe: A Profile of Western Europe (Edingurg-New York: Bartholomew Scribner, 1974). J. Frederick Dewhurst, John O. Coppock, P. Lamartine Yates et al., Europe's Needs and Resources: Trends and Prospects in Eighteen Countries (New York: Twentieth Century Fund, 1961). Reader's Digest, A Survey of Europe Today (London: The Reader's Digest Association, 1970), contiene datos sobre esquemas de consunción y de satisfacción económica, y las expectativas, por clases, de la renta, etc. Informes Económicos de la OCDE para Grecia. Italia, Portugal y España de 1977. Secretaría de la N.U. de la Comisión Económica para Europa, Economic Survey of Europe in 1976, 1. a parte: The European Economy in 1976 (New York: United Nations, 1977). La Fundación German Marshall, de los Estados Unidos; Fundaçao Caoustre Gulbenkian, Conferencia Internacional sobre Economia Portuguesa, 11 a 13 de outubro 1976 (Lisboa: Gulbenkian, 1977), 2 vols. 
Sin embargo, esto no debe llevarnos a la conclusión de que, incluso los países más pobres de la zona, deban ser clasificados como Tercer Mundo. La renta per cápita de Italia y España están por encima de la de todos los países latinoamericanos más importantes, incluyendo a la petrolífera Vene. zuela; incluso Portugal, el menos desarrollado de los cuatro, tiene una renta per cápita cercana a la de Brasil o México. En términos de desarrollo económico, forman parte del Segundo o Segundo-y-Medio Mundo. Son también países que, durante los últimos quince años, han tenido una baja tasa de crecimiento de su población, siendo la mayor la de España con el 1,1 por 100. Todos experimentaron un crecimiento considerable de su renta per cápita durante el período comprendido entre 1960 y 1975, con unas tasas de crecimiento porcentual anual que oscilaron entre el 3,9 por 100 en Italia y el 6,9 por 100 en Portugal; pero entre 1970 y 1975 no pudieron sostener esas tasas de crecimiento, y las mismas oscilaron entre el 1,7 por 100 en Italia y el 5,1 por 100 en España. Están caracturizados, por tanto, por un subdesarrollo relativo, con un crecimiento rápido primero en Italia y después en España, Grecia y Portugal; y posteriormente con un fuerte descenso de dicho crecimiento. Este problema fue particularmente agudo en Italia en la década de los setenta. En América Latina, solamente Brasil, con una tasa de crecimiento de la renta per cápita del 4,3 por 100 , creció entre 1960 y 1975 más rápidamente que Italia, el país de menor crecimiento entre los del Mediterráneo, que registró una tasa del 3,9 por 100.

Este cambio económico ha sido, principalmente, el resultado de un cambio gigantesco en la composición de la fuerza de trabajo ${ }^{3}$. Mientras en 1950 alrededor de la mitad de la población activa de España, Portugal y Grecia estaba ocupada en la agricultura, en Europa Occidental la proporción se situaba alrededor del 27 por 100. Durante 1970 ese porcentaje fue superado únicamente por Grecia, y en España ya estaba por debajo del 21 por 100; durante el mismo período fue del 44 por 100 en Yugoslavia y del 65 por 100 en Turquía. Para darse cuenta de la magnitud del cambio, podemos decir que llevó a los Estados Unidos desde 1880 a 1940 (y a Canadá desde 1901 a 1951) el pasar de los mismos niveles de 1950 a los de 1970 en Europa Sur. Estos cambios han afectado a los campesinos y trabajadores agrícolas diferencialmente $y$ han tenido diferentes ramificaciones en las diversas regiones de estos países. Se han creado nuevos problemas en el campo debido al envejecimiento de la población rural. En todas partes se han pro-

3 Sobre la estructura social, véanse: Margaret Scotford Archer y Salvador Giner (eds.), Contemporary Europe: Class, Status and Power (London: Weidenfeld and Nicolson, 1971), especialmente los capítulos de Herminio Martins (Portugal), Luciano Gallino (Italia), S. Giner (España) y Nikos Mouzelis y Michael Attalides (Grecia). Sobre España, véanse también: Amando de Miguel, Manual de estructura social de España (Madrid: Tecnos, 1974); Recursos humanos, clases y regiones en España (Madrid: Edicusa, 1977) y La pirámide social española (Esplugues de Llobregat, Fundación Juan March-Ariel, 1977). 
ducido dramáticos cambios en el modo de vida. Por ejemplo, los tres millones de trabajadores agrícolas no cualificados en España, se redujeron en 1970 a 986.000; en el mismo período, la mano de obra industrial creció de 2,5 a 4 millones -es decir, del 23,5 por 100 de la población activa al 30 por 100 -. y la fuerza no manual, de 2,8 a 4,7 millones -es decir, del 26,5 al 41 por 100 .

Estos cambios económicos y sociales han estado acompañados de una rápida urbanización, de tal forma que en 1972 el 9,6 por 100 de los espanoles vivían en Madrid, el 19,2 por 100 de los portugueses en Lisboa y el 29,7 por 100 de los griegos en el área de Atenas. Madrid era ya la tercera ciudad más grande de Europa Occidental y Roma era la cuarta. El Mediterráneo, el mundo de las «polis», es todavía principalmente el de las metrópolis - más que el de las pequeñas y medianas ciudades- y sufre de todos los problemas derivados de tal sobreurbanización.

En todos estos países existen grandes desigualdades en el desarrollo económico de las diferentes regiones. En 1962, en Grecia, la renta per cápita del Atica era de 156 con respecto a la media nacional (media $=100$ ), mientras que en las Islas Jónicas era de 58. En 1975, en España, las del País Vasco, Madrid y Barcelona estaban entre 139 y. 132, mientras que la de un gran número de provincias en el Sur y Oeste estaba alrededor de $60^{4}$. A estas desigualdades en la distribución regional de la renta hemos de añadir las relativamente grandes diferencias en la distribución de la renta por clases, lo cual, a veces, está agravado por las diferencias regionales. De acuerdo con una estimación, el índice de Gini era de 0,398 para Italia y de 0,425 para España $(0,355$ de acuerdo con otra), comparado con el 0,318 del Reino Unido y el 0,381 de Francia ${ }^{5}$. La parte correspondiente a jornales y de salarios ha ido aumentando sin embargo, y en algunos casos se ha reducido peligrosamente la proporción de beneficios, después de descontar los impuestos, en relación a la renta nacional; en España, por ejemplo, se pasó del 5,05 en 1973 al 3,31 por 100 en 1975. Pero aunque desigualmente distribuido, el crecimiento de la riqueza ha significado cambios radicales en el modo de vida, entrando los europeos del Sur a formar parte de la sociedad de consumo. En España, en 1960 , solamente un 4 por 100 de las familias tenían coche; en 1966 la cifra era del 12 por 100; en 1969, del 27 por 100, y en 1977 , del 51 por 100. Los propietarios de aparatos de televisión pasaron del 32 por 100 en 1966 al 90 por 100 en $1977^{\circ}$.

+ Banco de Bilbao, Renta nacional de España y su distribución provincial, 1975 (Madrid: Banco de Bilbao, 1975).

"Ministerio de Economía, Instituto Nacional de Estadística, La renta nacional en $197 t$ y su distribución (Madrid: Ministerio de Economía, Instituto Nacional de Estadística, 1977), pp. 111-135.

"DATA, Informes modelo Nacionales. 
Las relaciones sociales también experimentaron un gigantesco cambio con las variaciones en la composición de la fuerza de trabajo agrícola, las migraciones internas y externas, la urbanización, la adquisición de nuevas especialidades y el nuevo modo de vida. Los viejos esquemas de dependencia, las relaciones de clientela con los caciques locales, han sido ampliamente superadas por relaciones contractuales más impersonales y objetivas. Las desventajas derivadas de un bajo status y de los privilegios asociados con la posición social - por ejemplo, en relación con las autoridades- han sido reducidas drásticamente en el nuevo contexto. Parece, por tanto, poco probable que reaparezcan algunas de las formas de conflicto social que se manifestaron durante la Guerra Civil en Espan̄a, aunque están tomando su lugar conflictos nuevos y más institucionalizados. La población ha pasado de una economía de subsistencia y de un mercado laboral dominado por las relaciones personales, a una economía de mercado. Como consecuencia, los agricultores mediterráneos están más interesados actualmente por la relación entre la agricultura y otros sectores, por los subsidios gubernamentales para sus granos e incluso por los mercados exteriores, que por las rentas agrarias (las cuales, generalmente, están congeladas) o que por la adquisición de tierra por medio de la redistribución de las grandes fincas. Obviamente, todavía quedan zonas con trabajadores agrícolas sin tierra y con campesinos pobres, especialmente en el centro-sur de Portugal, siendo en estas zonas donde los comunistas han conseguido muchos votos. No obstante, los grupos económicamente marginales del sur de Europa se parecen cada vez más a aquellos de otros países — son los pensionistas, los ancianos, los minusválidos, los agricultores marginales y otros similares.

Han contribuido a estos cambios un número de factores comunes, como son: la preexistencia de modernos sectores susceptibles de expansión, particularmente las instituciones financieras y las empresas en algunas sociedades: la capitalización, hecha posible mediante el gran influjo de turistas, los cuales en 1970 contribuyeron en un 5,2 por 100 al PIB en España, y en menor proporción, en un 2,1 por 100 , en Grecia; las remesas de gran número de trabajadores emigrantes a los países más ricos de Europa, y las inversiones extranjeras, que desempeñaron un importante papel en Grecia.

La proximidad de las naciones ricas de Europa ha representado una oportunidad y también uno de los focos de tensión de la zona, puesto que las economías de los países al Sur están estrechamente ligadas a aquellas de la CEE y son, por tanto, fuertemente dependientes de la prosperidad europea. Mientras la participación de la agricultura en el producto nacional ha descendido (en España es actualmente del 12,7 por 100, comparado al 5,2 por 100 entre los Nueve), la parte de exportaciones agrícolas es todavía importante, llegando al 30,7 por 100 en Grecia. En este contexto, la entrada en el Mercado Común y en la Política Agrícola Común adquiere espe- 
cial significado ${ }^{7}$. Mientras en 1971 la CEE absorbió entre el 45 y el 50 por 100 de sus exportaciones, la participación de los Estados Unidos osciló entre el 6 por 100 en Italia y el 16 por 100 en España. El bache tecnológico y la dependencia resultante añaden otra pesada carga a la balanza de pagos.

Los cambios políticos que sobrevinieron con el final del autoritarismo han permitido a la clase trabajadora presionar para lograr una mayor participación en la renta nacional. En España, los jornales, los salarios y las contribuciones de las empresas a la Seguridad Social representaron en 1974 el 61,85 por 100 de la renta nacional neta; la cifra llegó al 63,96 por 100 en 1975 y al 66,67 por 100 en 1976 - una redistribución aproximadamente igual a aquella de la década anterior-. Al mismo tiempo, el excedente neto de explotación de las empresas descendió -de 9,59 por 100 en 1974 a 8,11 por 100 en 1975 y a 5,85 por 100 en 1976 — $^{*}$. En Portugal, la parte de jornales, salarios y contribuciones a la Seguridad Social se elevó del 49,1 por 100 en 1973 al 53,5 en 1974 y a cerca del 62 por 100 en 1975 ; en 1976 descendió al nivel de $1974^{\circ}$.

Mientras en 1976 la tasa de inflación en los países europeos de la OCDE fue del 11,2 por 100, la tasa española fue del 19,8 por 100, y en Italia, del 21,3 por 100; España e Italia fueron los dos únicos países de la OCDE en los que la tasa se elevó por encima de la del año anterior. En Portugal, durante el verano de 1974 , la inflación alcanzó el 25 por 100. También aumentó el desempleo en España, pasando del 3,22 por 100 de la población activa en 1974 al 5,5 por 100 en 1976. En Portugal se elevó del 2,5 por 100 de la población activa en 1970 al 13,6 por 100 en 1975. En dicho país el retorno de emigrantes a Europa - los «retornados» de las colonias (se estima que representaban entre un 5 y un 9 por 100 de la población)-, añadido a los efectos de la recesión económica, hizo aumentar en 1977 la población desempleada hasta un 18 por 100 oficial. (De acuerdo con algunas estimaciones, fue un 25 por 100 de la fuerza de trabajo.)

Internacionalmente, los países del Mediterráneo han estado integrados sólo parcialmente en el sistema político, económico y militar de Occidente. Unicamente Italia es miembro tanto de la Comunidad Europea como de la NATO. Mientras Portugal y Grecia aspiran a entrar en la CEE -y ambos son miembros de la NATO-, España, otro aspirante a la integración comunitaria, no es miembro de la NATO; más aún, su entrada en la alianza defensiva no es segura, aunque tenga con la misma una relación especial debido

${ }^{7}$ Christian Heimpel, La cooperación de la CE con la Europa del Sur: algunos problemas de la integración de la agricultura portuguesa en el Mercado Común, Conferência Internacional sobre Economia Portuguesa, vol. I, pp. 253-267.

- Banco de Bilbao, Informe Económico, 1976 (Madrid: Banco de Bilbao, 1977), página 71 .

* German Marshall Fund, Fundaçao Calouste Gulbenkian, Conferencia Internacional sobre Economia Portuguesa, vol. I, p. 445. 
al acuerdo militar con los Estados Unidos. España y Grecia tienen con sus vecinos problemas que no encajan en el esquema de las relaciones EsteOeste y que, aunque centrales para ellos, son para sus amigos europeos solamante marginales y perturbantes. Eston son, específicamente, el conflicto español con el Reino Unido acerca de Gibraltar, el problema más reciente de la devolución de su primera colonia en el Sahara a Marruecos y Mauritania y —en el otro lado del Mediterráneo- las tensiones greco-turcas acerca de Chipre y del Egeo. Estos conflictos han creado necesidades de defensa y problemas de alianzas que no encajan bien en el sistema defensivo occidental. La presencia de los partidos eurocomunistas en Italia y España (con altas aspiraciones de convertirse en "Koalitionsfabig») y de los partidos socialistas con una tendencia neutralista, y un sentimiento de simpatía por el Tercer Mundo, así como algunas conexiones con los partidos socialistas de los Estados Arabes, hacen que la cuestión de la integración en el sistema defensivo de Occidente sea más cuestionable en ambos lados. España, neutral en cierto modo en las dos guerras mundiales, ha estado aislada del sistema continental de alianzas desde los tiempos de las guerras napoleónicas. Su distancia de la Europa Oriental, el hecho de que no fuese liberada por los Aliados después de la Segunda Guerra Mundial y su tendencia a culpar la supervivencia del régimen de Franco, en algún grado, en el deseo de los Estados Unidos de alcanzar acuerdos que sirviesen a sus intereses, ha diferenciado su política extranjera visto desde la perspectiva de los países más cercanos al poder soviético.

El capitalismo en cualquiera de sus variantes - deside las economías de libre mercado a las llamadas "Soziale Marktwirtschaft» pasando por los prósperos sistemas económicos mixtos de las naciones del norte de Europa- no ha obtenido completa legitimidad en ningún país sur europeo, incluyendo a Francia ${ }^{10}$. Se podría debatir acerca de si la falta de interés es el resultado de la presencia de fuertes partidos comunistas, así como la de los partidos socialistas maximalistas, o si su presencia es el resultado de la falta de legitimidad. El capitalismo no se estableció satisfactoriamente en ninguno de estos países, anteriormente o al mismo tiempo, que la democracia liberal. Las élites precapitalistas y la fuerte Iglesia católica nunca aceptaron la ética del capitalismo, y un desarrollo capitalista o industrial pequeño no podía satisfacer a las masas trabajadoras con un nivel de vida aceptable.

"En España, en enero de 1977, el 39 por 100 eligió la palabra "socialismo" y el 30 por 100 eligió "propiedad privada"; el 11 por 100 eligió ambas y el 20 por 100 no expresó su opinión. Cuando se preguntó sobre cómo se deberían llevar las empresas, el 16 por 100 contestó que por sus propietarios, el 42 por 100 contestó que los propietarios y el personal debían participar, el 5 por 100 estaba a favor de la propiedad y dirección estatal y el 29 por 100 quería que la propiedad fuese de los trabajadores y que la dirección la llevasen unos representantes de éstos; el 9 por 100 no contestó. De los que estaban a favor de la socialización, sólo un 11 por 100 lo estaba de la expropiación sin compensación. 
En España, y en menor medida en Portugal, el desarrollo económico capitalista tuvo lugar durante mucho tiempo bajo un régimen autoritario que no permitió el surgimiento de un movimiento sindicalista que hubiese institucionalizado los conflictos económicos de clase y forzado en los momentos de prosperidad una redistribución más equitativa de la renta nacional. En mayor o menor grado - ciertamente menos de lo que los ideólogos de la izquierda proclamaran-, el desarrollo se ha llevado a cabo por medio de un capitalismo dependiente con la presencia de corporaciones multinacionales, que pueden llegar a ser el foco de una hostilidad de la izquierda-socialista nacionalista. El importante papel desempeñado por las instituciones financieras en el desarrollo económico de estos países - percibido fácilmente como oligárquico y privilegiado, en contraste con su papel bajo un capitalismo más empresarial como el de otros países de Europa y Estados Unidos-, hace de los bancos un blanco internacional. En Portugal, esta percepción ha facilitado una socialización en gran escala, ya que los bancos controlan gran parte de la economía - como, en menor medida, también hacen en España.

A nivel ideológico y verbal, el anticapitalismo fue tolerado por los regímenes autoritarios, que además incorporaron el corporativismo católico ", las tradiciones antiliberales, así como la herencia de la ideologia fascista. Este trasfondo - la falta de empatía por los negocios entre amplios sectores de las clases medias que emergieron del desarrollo inicial del Estado moderno (los burócratas y las profesiones liberales) y las tensiones entre las capitales más burocráticas y políticas, como Madrid y Roma, y las más comerciales y empresariales, como Barcelona o Milán- explica la falta de legitimidad acordada a la burguesía industrial y comercial entre las otrora clases medias conservadoras. Este anticapitalismo tan y tan poco latente colorea la imagen de los Estados Unidos, e incluso de las democracias europeas en las que los partidos socialdemócratas han levantado la utopía de una economía plenamente socialista. El triunfo intelectual del marxismo entre las generaciones que crecieron durante las protestas estudiantiles de finales de los sesenta y principios de los setenta, y la afinidad del pensamiento intelectual en estos países, basado en el racionalismo y sistemas éti-

"En respuesta a la pregunta ¿Puede uno ser un buen comunista y un buen católico al mismo tiempo? (enero 1977), el 32 por 100 dijo sí, y el 56 por 100, no - una cifra cercana a la de Italia en 1963 , con el 28 y 56 por 100 , respectivamente-. En 1973, en Italia, varió la proporción al 55 y 34 por 100. En España, el lugar ocupado en la escala derecha-izquierda correlacionó 0,46 con la religiosidad. comparado con el 0,09 con la renta y el 0,21 con la educación. Entre los votantes madrileños del PCE, el 16 por 100 se declaró ateo, el 36 por 100 indiferentes (comparados al 6 y 14 por 100 entre los del PSOE). El 7 por 100 de los votantes del PCE declararon ser católicos practicantes, frente al 22 por 100 de los votantes del PSOE, el 51 por 100 de los votantes de UCD y el 74 por 100 de los adeptos a AP (DATA, informes). 
cos (quizá de herencia católica), han contribuido a la hegemonía intelectual del pensamiento marxista en la actualidad.

Con la excepción de Grecia, un país greco-ortodoxo, las dos penínsulas mediterráneas son católicas. Pero en el curso del siglo xIx, y quizá incluso anteriormente, tuvieron lugar varias crisis religiosas serias, provocadas inicialmente por un anticlericalismo y posteriormente por las consecuencias indirectas derivadas del cambio en la posición económica de la Iglesia después de la venta de bienes de manos muertas llevada a cabo por los liberadores revolucionarios. Esto hizo a la Iglesia dependiente de la burguesía y contribuyó al anticlericalismo e incluso a la indignación moral antirreligiosa de los movimientos obreros socialistas, y más particularmente de los anarquistas. La poderosa posición institucional de la Iglesia y la hostilidad que encontró entre los reformistas-liberales y posteriormente en el movimiento obrero, la tornó en muchas partes de estos países hacia posiciones ultraconservadoras, que más adelante aceleraron la alienación de sectores importantes de la clase media, y especialmente de las clases trabajadoras urbanas y rurales. En la actualidad aún permanecen los viejos conflictos, particularmente la emisión de ayuda pública para la educación privada. La izquierda, y más específicamente los eurocomunistas, han optado por abrir la mano a los católicos, deseosos de aceptar su papel en la sociedad y de unírseles en determinadas campañas. Esta política, la conciencia de su propia debilidad - particularmente la falta de organizaciones que absorbe- y, sobre todo, la heterogeneidad ideológica y la crisis interna que se inició, cristalizó o aceleró en el Concilio Vaticano II, han dado por resultado un cambio radical de la posición de la Iglesia en estas sociedades. En el caso de España, su identificación con el régimen de Franco - resultado de las políticas anticlericales de la República y de la persecución religiosa que tuvo lugar al comienzo de la Guerra Civil- ha sido cuestionada por las nuevas generaciones de líderes católicos laicos y religiosos; la crítica de lo pagado por la colaboración con el régimen reflejan una nueva conciencia social. Hay católicos laicos identificados con el partido comunista, e incluso aparecen sacerdotes bien conocidos en reuniones comunistas. Pero la presencia de un catolicismo de izquierdas, articulado sin embargo, verbal e intelectualmente, no debe esconder el hecho de que la religión continúa siendo, en todos los países del Mediterráneo católico, la variable decisiva que explica las preferencias electorales moderadas y conservadoras de los votantes. De hecho, es un factor más importante que la clase social. En el caso de un conflicto real entre la Iglesia y el Estado, la Iglesia católica todavía podría movilizar a grandes sectores del electorado. Los líderes religiosos pueden ayudar a deslegitimar el sistema económico y social existente, particularmente el capitalismo. Pero, al mismo tiempo, la subcultura católica es uno de los obstáculos que se encuentra constantemente la izquierda en su marcha hacia la hegemonía.

En resumen, mientras los problemas estructurales, y particularmente los 
económicos, son centrales en el futuro de la Europa Sur - de hecho son la fuente inmediata de algunas de sus preocupaciones-, en esta zona del mundo la "politique d'abord» es todavía dominante. Los valores tecnocráticos que dominan a muchos de los concilios de la Nueva Europa, los difíciles pactos entre los intereses organizados corporativamente -especialmente los sindicatos y empresarios--., el importante papel desempeñado por los funcionarios y expertos en servir o imponer en el Norte o en gran parte de Europa Occidental sus elecciones sobre los dirigentes políticos, no es el esquema legítimo dominante o al menos el más visible de las políticas en el sur de Europa. Se debaten grandes cuestiones políticas y se evocan modelos alternativos sobre el orden social y económico; florecen las publicaciones simbólicas, se formulan dilemas sobre polírica exterior en términos ideológicos, y en España, incluso, se está cuestionando la unidad del Estado creado hace más de cuatro siglos por una pequeña minoría de la población vasca (estando incluso una porción aún más pequeña dispuesta a utilizar la violencia para conseguir su propósito). La juventud $y$, en cierto modo, la inexperiencia de la nueva clase política de las nuevas democracias ${ }^{12}$, la débil institucionalización en España y Portugal de grupos de presión de reciente organización, como el comunista - los cuales están considerados como fuera del sistema en Portugal y en España, e incluso en Italia-, de legitimidad dudosa por parte de varios sectores de la población, hacen el debate político agudo y potencialmente peligroso. (En Grecia, el recuerdo del levantamiento comunista y la consiguiente guerra civil es aún más pernicioso.) El debate polí. tico, aun cuando no sirva para resolver las cuestiones políticas, conduce a una negligencia relativa y a una intratabilidad de algunos de los problemas económicos más comunes e inmediatos y a sus consecuencias sociales. Algunos de estos problemas son realmente insolubles -como el status de los vascos - o difíciles de resolver - como la integración de los partidos comunistas en el sistema político democrático (a pesar de los esfuerzos casi heroicos de algunos eurocomunistas). Sin embargo, su solución es de muchas maneras una precondición para el continuo progreso económico, al que las poblaciones de estos países se ha acostumbrado tan rápidamente. La incertidumbre acerca del sistema económico del futuro, a pesar de las victorias electorales de los conservadores moderados y de la negación de su retórica ideológica por parte de los líderes de la izquierda, puede hacer que el continuo desarrollo económico capitalista sea más difícil; mientras tanto, la fuerza que tienen los intereses conservadores y la integración de estos

12. El promedio de edad de los diputados de la UCD, en las Cortes Españolas elegidas en junio de 1977, era de 44,3 años; el del PSOE. de 43,5, y el de los miembros de la Comisión Constitucional, de 44,9 años. Entre los diputados del PSOE, el 35 por 100 estaban por debajo de los 35 años (nacidos en 1943 o posteriormente), y el 60 por 100 de los diputados de UCD estaban por debajo de los 45 años. 
países en el sistema económico occidental hacen muy difícil, casi imposible, una rápida transición al socialismo, excepto a un precio extremadamente alto. Esta ambivalencia fundamental no es muy diferente de la resaltada por el líder socialdemócrata Treves en marzo de 1920: «Esta es la tragedia de la presente crisis. Ya no pueden imponernos por más tiempo su orden y nosotros todavía no podemos imponerles el nuestro» ${ }^{13}$.

Si hay una palabra que define más claramente la situación de Europa del Sur que en otras partes de Europa, ésta es «ambivalencia» -ambivalencia respecto al presente y al futuro, en política, economía y en la posición internacional-. Esta ambivalencia profunda hace ambigua la situación. Paradójicamente, los grandes cambios económicos y sociales de la última década y media, e incluso el cambio más dramático hacia la democracia -largamente esperado por grandes sectores de la población, es bienvenido por la mayoría de aquellos deseosos de guardar en el pasado al gobierno autoritario, a lo que se oponen sólo unos cuantos-, no ha creado confianza en el futuro y en las esperanzas compartidas. La esperanza en la izquierda en el nuevo orden político, la desilusión de sus sustentadores en materia económica, los temores, que son expresados, más o menos abiertamente, en el terreno político y económico por aquellos que tienen más que perder por alguno de los cambios invocados, tienen que ver con la ambigüedad fundamental de la situación. Existen escenarios alternativos especulativos en la zona y en cada uno de los países, y algunos de éstos son bastante inquietantes. Por otro lado, existen claras indicaciones, por parte de grandes sectores de la población de estos países, de un fuerte deseo de estabilidad, de libertad dentro del orden democrático, de continuidad del crecimiento económico y de cierto grado de cambio social. A pesar de la impresión que uno pueda sacar de la lectura de ciertas fuentes o de la escucha de los rumores retóricos y miedosos de otras, ni una reacción revolucionaria, ni una autoritaria, tendrían amplio consenso actualmente. Esas alternativas tendrían éxito únicamente si falla el liderazgo responsable del sistema político democrático, si crea innecesariamente problemas insolubles, si no es capaz de mantener las cosas bajo control frente a las violentas minorías activas listas para producir el desorden entre las fuerzas que soportan el sistema, o si no maneja adecuadamente, sólo o con la ayuda exterior, los apremiantes e inmediatos problemas económicos. Los problemas pueden ser resueltos si la dirección democrática, para usar una frase de Ortega y Gasset, está «a la altura de las circunstancias» - con algunas excepciones-, lo que permitiría a las democracias del sur de Europa consolidarse o reequilibrarse.

1. Claudio Treves, citado por Christopher Seton-Watson, Italy from liberalism to fascism, 1870-1925 (Methuen, Londres, 1967), p. 560. 
España, Portugal y Grecia: nuevas democracias en tiempos dificiles

En Italia las instituciones democráticas, a pesar de sus fallos, han echado raíces mediante un sistema de partidos bien atrincherado, basado en unas subculturas altamente integradas. Pero en España la democracia acaba de ser instituida. Aquí el sistema de partidos está incoándose todavía y el partido dominante en el Gobierno está sin miembros, no basándose, como la Democracia Cristiana en Italia, en una comunidad subcultural. En Italia las cuestiones son las siguientes: ¿hasta dónde pueden llegar la crisis y la supervivencia sin gobierno? ¿Hay cabida para una reestructuración del sistema democrático o, al menos, para su supervivencia sin un corte? En Grecia, Portugal y España la cuestión es: ¿se consolidará la democracia? Existen afinidades fundamentales entre España y Portugal, las cuales llegaron tarde a la democracia después de cuarenta y siete y treinta y seis años, respectivamente, de gobierno autoritario ${ }^{14}$.

También existen algunas diferencias que merecen un breve análisis. En España, el mandato de Franco fue establecido después de una sangrienta guerra civil que duró tres años y dividió a una generación entera de españoles (afortunadamente, ahora es una generación envejecida). En Portugal, el régimen de Salazar subió al poder sin un corte tan dramático con el pasado. Más bien, evolucionó de la desintegración y crisis de una democracia que no había movilizado políticamente a grandes sectores de la población. Aunque el régimen, particularmente en sus últimas fases, dejó algunas cicatrices, no engendró nada comparado a los amargos recuerdos de la Guerra Civil española. Además, el régimen de Caetano, después de un frustrado esfuerzo de transformación interna, fue depuesto mediante un rápido y satisfactorio golpe militar, acompañado por el entusiasmo de la revolución de los claveles ${ }^{15}$. El cambio de régimen fue el resultado de un problema insoluble, generado por unos líderes incapaces de enfrentarse a la descolonización, de las frustraciones del ejército colonial y del coste de una guerra que sobre-

14 Sobre el último período del régimen franquista, el entramado institucional y el juego de las fuerzas implicadas en el cambio (en inglés), véanse: José Amodia. Franco's Political Legacy: From Dictatorship to Façade Democracy (Penguin, Londres, 1977); William T. Salisbury y James D. Theberque (eds.), Spain in the Seventies and Beyond: Problems of Change and Transition (Praeger, New York. 1976); Paul Preston (ed.), Spain in crisis. The evolution and decline of the Franco Regime (Harvester, Hassocks, Sussex, 1976). Un ensayo informativo de las elecciones de junio de 1977 es la de Lothar Maier, Spaniens Weg Zur Demokratie (Anton Hain, Meisenheim am Glan, 1977).

1 Para un análisis teórico sobre la caída de los regímenes autoritarios, véanse Philippe Schmitter, Liberation by Golpe: Retrospective Thoughts on the Demise of Authoritarian Rule in Portugal, Armed Forces and Society, 2 (noviembre 1975), pp. 5-33; Giuseppe di Palma, Italia, Portogallo, Spagna: Ipotesi su tre Regimi Alla Prova. Prospettive Settanta, 3 (enero-marzo 1977), pp. 42-61; es un informe estimulante sobre los problemas de la continuidad y de la transición en la política de estos países. 
pasaba los recursos de un pequeño e internacionalmente aislado país enrolado en un conflicto sin esperanza. El nuevo régimen podía ofrecer confianza respecto a la finalización del problema, aunque la forma en que fue resuelto - la rápida descolonización sin planificar- dejó el amargado legado del regreso de Angola; en la actual situación económica, estas ex colonias -al contrario de los «pieds noirs» en Francia e incluso los «Heimatvertriebene» en Alemania y Finlandia después de la guerra- no pueden ser incorporadas efectivamente en la economía y en la sociedad.

Por el contrario, el régimen de Franco -aunque con una creciente oposición y enfrentado a un problema insoluble en el País Vasco, estaba decayendo rápidamente en los últimos años- murió solamente con la muerte de su fundador y con la decisión de sus más importantes sustentadores de dirigirse, lentamente al principio y expeditivamente después, hacia la democracia $^{16}$. El cambio en Portugal abarcó al Ejército; el «Movimiento das Forças Armadas» (MFA) tomó la decisión y dio poder a los jóvenes capitanes para llevar a cabo el cambio revolucionario de la sociedad. Aunque el MFA se ha convertido en las «Forças Armadas Portuguesas» (FAP) y los líderes más relevantes de la revolución militar han sido desplazados, el Ejército conserva una posición muy especial; los candidatos a la presidencia de la República fueron militares, y nadie pensó que un civil pudiese reclamar el puesto. Los partidos políticos, que inicialmente ocuparon un lugar secundario y cuya ascendencia dependió de los lazos que lograron establecer con los jóvenes oficiales, fueron recuperando lentamente el terreno que habían dejado en el acuerdo con el MFA antes de las elecciones para la Asamblea Constituyente; estas elecciones establecieron realmente una dualidad entre el MFA y los partidos, llevando a un pacto que daba el poder de veto, e influencia constitucional, en todas las esferas de toma de decisión, al Consejo de las Fuerzas Armadas. Se podría preguntar si dicha dualidad encaja realmente en la definición de la democracia.

En España, la transición ha sido más suave, y fue llevada a cabo de acuerdo con las previsiones constitucionales formales establecidas en las Leyes Fundamentales de Franco; el paso decisivo para llegar a una Asamblea elegida directamente, que realizase una nueva Constitución, fue llevado a cabo por las viejas Cortes, nombradas en su mayoría por Franco, en noviembre de 1976. La transición ha sido un claro ejemplo de cambio constitucional contrario al espíritu de la Constitución, pero realizado constitucionalmente - lo que los alemanes llamarían «verfassungwidrige Verfassungsän-

1* Juan Linz, Spain and Portugal: Critical Choices, en David Landes (ed.), "Western Europe. The Trials of Partner-ship" (D. C. Heath, Lexington, Mass., 1977), pp. 237-296, y las fuentes citadas alli; Ferdinand A. Hermes y Peter-Hugo Köppinger, Von der Diktatur Zur Demokratie: Das Beispiel Spaniens un Portugals, en Verfassung un Verfassungswirklichkeit, 10 (enero 1976): 13-190; Giuseppe de Vergottini (ed.), Una eonstituzione democratica per la Spagna (Franco Angeli, Milán, 1978). 
derung»-, y en este aspecto no difiere mucho de la transición, realizacta a través del esquema formal de la Constitución de Weimar, a la dictadura nazi. Este tipo de transición tiene sus ventajas, pero también sus inconvenientes. La democracia disfruta de una legitimidad formal derivada de la legalidad, incluso entre aquellos que no están contentos con el cambio, y esta fórmula, llamada en el lenguaje político español «reforma», ha hecho más fácil la aceptación de la democracia para un ejército cuyas miras políticas son tan diferentes de las del ejército portugués. El golpe militar portugués y las transformaciones internas realizadas por el MFA dentro de las fuerzas armadas - lo que permitió a los militares jugar un papel político-, condujo a un cambio interno muy diferente en las fuerzas armadas; en España, el ejército está al lado y al margen del proceso llevado a cabo por los civiles. Otro elemento de continuidad con el pasado, con todas las ambivalencias relacionadas con el hecho, es Juan Carlos I. El joven rey ha confrontado la difícil tarea de combinar en su instauración las contradicciones derivadas del planteamiento hecho por Franco (intentando dar una continuidad al sistema dictatorial) y su propia decisión de optar por una monarquía constitucional, lo que contribuyó decisivamente a la instalación de las instituciones democráticas. Juan Carlos se ganó el apoyo popular por él mismo $y$, por tanto, para la institución monárquica, que no disfrutaba ya de la legitimidad tradicional en otras democracias europeas. Las democracias del sur de Europa ofrecen una oportunidad interesante para comparar el papel que desempeñan los presidentes electos, con todas las complejidades que conllevan las políticas presidencialistas, con la relativa continuidad y estabilidad de una monarquía ${ }^{17}$.

Tanto los españoles como los portugueses tienen sistemas multipartidistas, pero existen algunas diferencias fundamentales entre ellos ${ }^{18}$. Ningún

17 La monarquía que cayó en 1931 había limitado su legitimidad tradicional, y su instauración por Franco no contribuyó a esa legitimidad: aun así, cuando se preguntó a la población (enero 1977) para elegir entre varias dicotomías políticas, monarquía o república, el 59 por 100 eligió la monarquía, el 18 por 100 la república y el 19 por 100 permaneció indiferente. Sin embargo, el importante papel desempeñado por Juan Carlos como moderador del poder fue aprobado por el 72 por 100 , habiendo solamente un 25 por 100 crítico. Aún más significativo es ese 42 por 100 de aquellos que, en un principio a favor de la república, vieron favorablemente las acciones del rey; el rey estaba, en un sentido, legitimizando las instituciones. En este sentido, podemos decir que el general Eanes en Portugal, un presidente elegido popularmente, puede jugar, en la presente situación de crisis, un papel independiente como "poder neutral" por encima de los partidos.

18 Véase Giovanni Sartori, Parties and Party Systems: A Framework for Analysis (Cambridge University Press, England, 1976); para una tipolgoía del sistema de partidos utilizado en nuestro análisis, véanse: Jorge Caspar y Nuno Vitorino, As eleiçoes de 25 de abril: geografia e imagen dos partidos (Horizonte, Lisboa, 1976, es un excelente estudio de la ecologia electoral y un análisis de los símbolos utilizados por los partidos. Para las posiciones programáticas de los partidos y el texto del acuerdo entre los mismos y el MFA, véanse: 1975 primeiras eleiçoes livres (Decibel, Lisboa, 1975), y Francisco Pereira de Moura et al., Esclarecer o eleitor: inquerito a os partidos politicos (Afrodite, Lisboa, 1974). 
partido español (hasta ahora) ha sido capaz de obtener el 37,9 por 100 de los votos que obtuvieron los socialistas portugueses en 1975. La Unión de Centro Democrático (UCD), el partido de Suárez, tuvo solamente el 34,85 por 100 de los votos en 1977 -aun cuando ganaron el 47,1 por 100 de los escaños- ${ }^{19}$. En España hay partidos regionales que consiguieron alrededor de un 7 por 100 de los votos y obtuvieron 19 de los 350 escaños de la cámara baja. Estos partidos no existen en Portugal, ya que es una de las naciones-estado más antiguo y culturalmente homogéneo de Europa. El Partido Comunista de Portugal, el PCP, obtuvo el 12,5 por 100 de los votos en 1975, a lo que debe añadirse el 4,1 por 100 del MDP, partido simpatizante del comunista; en 1976, después de la desintegración del MDP, obtuvo el 14,6 por 100. Los comunistas españoles tuvieron menos éxito, obteniendo solamente el 9,3 por 100 de los votos. Sin embargo, esas vueltas electorales dicen muy poco acerca del papel que desempeñaron los partidos comunistas en sus respectivas sociedades. El período semirrevolucionario que precedió a las elecciones permitió al PCP asumir una posición de control en la Intersindical, la federación sindical, mientras que los compañeros españoles tienen que combatir abiertamente con otras organizaciones sindicales. El período inicial de la democracia portuguesa permitió al PCP consolidar lo que en Portugal se llama el «poder social», una especie de influencia más fuerte que la «presenza» comunista italiana. Existen grandes zonas en Portugal en las que el PCP obtuvo una amplia mayoría - la provincia industrial de Setubal, al sur de Lisboa, y Evora y Beja, dos provincias agrícolas, donde obtuvieron alrededor de un 40 por 100 de los votos y consiguieron aumentos considerables entre las dos elecciones-. No existen logros comunistas semejantes en las provincias españolas. Por otro lado, el PCP portugués se encuentra mucho más aislado que el PCE español. Su implicación en el golpe militar de noviembre de 1975, del que se retiró justo a tiempo, y su intento de conseguir la hegemonía durante 1975, crearon una desconfianza generalizada no sólo a la derecha del centro, sino también dentro del Partido Socialista portugués. Parece dudoso que lleguen a estar «Koalitionsfähig» en el futuro próximo.

${ }^{14}$ Las elecciones de 1977 todavía no han sido objeto de un análisis exhaustivo. Algunas de las primeras reflexiones acerca del tema, inmediatamente después de la publicación de las vueltas electorales, pueden ser estas cuatro: Javier Tusell, Un primer análisis de los resultados electorales, en Club Siglo XXI, "La Corona y la nueva sociedad española ante un año histórico", vol. 2 (Fomento Editorial, Madrid, 1977), pp. 711-729; Juan Linz, Un sociólogo ante la primera elección democrática, en igid., pp. 731-759; Dario Vila Carro, Francisco Andrés Orizo y Manuel Gómez-Reino, Sociología del actual cambio político en España, en FOESSA, "Sintesis actualizada del III Informe FOESSA 1978" (Madrid); Carlos Huneus y Dieter Nohlen, Das Spanische Parteiensystema in der Dynamik des Demokratisierungsprozesses: Versuch Einer Systematisierung, en "Der Bürger im Staat", 27 (1977): 96-98. Véase Pedro J. Ramírez, Asi se ganaron las elecciones (Planeta, Barcelona, 1977), para ver un informe periodistico sobre la campaña. 
El PCE español está en la diestra dirección de una vieja mano política que incluso ya antes de la guerra civil era la cabeza de la Organización de las Juventudes Socialistas españolas; ha hecho que su extremada posición eurocomunista sea sorprendentemente fiable, renunciando al leninismo $y$ a muchos de los símbolos del pasado, y sigue una política dirigida hacia la consolidación de las instituciones. Esta estrategia puede no compensar mucho en cuanto a votos, pero ciertamente hace las cosas más difíciles a los viejos anticomunistas; $y$ aunque existe una fuerte competencia sindical entre Comisiones Obreras (comunista) y la Unión General de Trabajadores (socialista), hay más cabida para la cooperación sobre materias específicas de la izquierda en España que en Portugal. La geografía electoral misma presenta a los partidos de la izquierda ante el dilema de o bien conceder un número de escaños en los gobiernos locales a la UCD, o dirigirse hacia un frente popular; sumando los votos de los socialistas y de los comunistas, se acercan a una mayoría, si no a una completa mayoría, en muchas de las municipalidades españolas. La geografía electoral de Portugal impone raramente la oportunidad y la necesidad de una cooperación de la izquierda.

Otra diferencia importante entre los dos sistemas de partidos es que, después de que los partidos del ala-derecha nacientes fuesen proscritos (siguiendo la salida de Spinola), ningún partido portugués puede clamar por la continuidad y lealtad al pasado autoritario, como hizo la Alianza Popular española (AP) en su congreso y en las elecciones -aun cuando el mismo se remitía a las nuevas instituciones democráticas-. En España no existe ningún partido neofascista como el italiano MSI, el cual está fuera del «arco costituzionale» y excluido de las coaliciones representadas en el Parlamento; pero para un importante sector de la opinión pública española, la AP, a pesar de sus esfuerzos, no es un partido del sistema. El sistema de partidos portugués es a este respecto menos centrífugo y encaja débilmente en el modelo de sistemas extremos polarizados y multipartidistas de Sartori. De hecho, mientras el PCP permanezca aislado, el Partido Socialista Portugués (PS), con el 35 por 100 de los votos; el Partido Social Democrático (PPD), con el 24 por 100, y el Centro Democrático Social (CDS), que con su 15,9 por 100 de los votos se acerca a un partido demócrata-cristiano, pueden operar como el modelo de sistemas multipartidistas limitados de los países de Europa del Norte y Central. El PS ha mostrado poca disposición a jugar dicho juego y ha preferido, en cambio, forzar a otros partidos a aceptar una minoría socialista en el Gobierno, incluso cuando las coaliciones alternativas estaban dispuestas a ello. Sin embargo, en enero de 1978 , Soares se vio forzado a aceptar a tres miembros del CDS en el Gabinete, cuya caída en agosto dirigiría, después de que los partidos demostraran ser incapaces de formar una coalición en un Gabinete apoyado y sustentado presidencialmente y de la (temporal) casi exclusión de los partidos. Es difícil imaginar que en España, con la presencia del PCE y de AP, con los dos 
partidos dominantes: el Partido Socialista Obrero Español (PSOE) y la UCD en el centro del espectro, se limitarían a competir cada uno con el otro más que a intentar atraerse votos, o como en el caso del PSOE, intentar conseguir aquellos de sus alas derecha e izquierda - como se derivaría del modelo de Sartori de multipartidismo extremo polarizado.

Otra diferencia entre España y Portugal es el nivel de desarrollo económico. Portugal era una nación mucho más subdesarrollada. En 1975, su PIB fue de 15.000 millones de dólares -el español fue de 97.140 millones de dólares_-, y sus respectivas rentas per cápita fueron de 1.570 y 2.750 dólares. No puede ignorarse la diferente escala de la economía cuando ambos se enfrentan a la crisis; sacar a Portugal de sus problemas es muy diferente de sacar a España. Además, el desarrollo económico reciente de Portugal, el relativo atraso de gran parte del campo, la falta de participación de grandes sectores de su población en la sociedad de consumo, hacen que el contraste entre la expectación y la desilusión con la situación económica actual sea menos visible y dolorosa de lo que lo es en España, donde, durante la última década y media, las masas empezaron a participar en la prosperidad de los sesenta. En Portugal es todavía posible el regreso al campo, que al norte de Lisboa está constituido por pequeñas propiedades de agricultura de subsistencia; sin embargo, muchos de los emigrantes a las ciudades españolas vendieron sus propiedades rurales, si es que las tenían, y la pérdida de un trabajo, con lo que el consiguiente retorno al pueblo sería insoportable. Existe también una diferencia fundamental entre la clase empresarial de los dos países: en Portugal es pequeña, concentrada regionalmente, familiar y fuertemente oligárquica; en España es mucho mayor y más social, y geográficamente es más heterogénea. Si España hubiese experimentado una crisis económica y social similar a la que ha experimentado recientemente Portugal, dudo de si la sociedad española y sus instituciones conservadoras hubiesen aguantado la tormenta. Desde un punto de vista estrictamente económico, Portugal - particularmente después de la pérdida de su imperio colonial y del desastre económico creado, tanto en la ciudad como en el campo por la socialización-, puede que se vea menos afectada que España en su estabilidad social. Puede ser que España lo sienta más debido a su mayor nivel de desarrollo, mayor capital y recursos empresariales y un nivel de vida mucho mayor de sus masas. Más aún, una crisis económica profunda en España sorprendería al Gobierno, sin las reservas acumuladas durante el mandato frugal de Salazar, cuya mentalidad era más bien la de un ministro de finanzas que la de un ministro para el desarrollo económico. La economía española, aunque es mucho más dinámica y está más ligada al sistema económico internacional, e inclinada hacia la inversión y el desarrollo más que al equilibrio de su balanza, es potencialmente más vulnerable que la portuguesa. Los cambios revolucionarios que han tenido lugar en Portugal, aunque económicamente costosos y en parte sujetos a revisión, 
han producido cambios profundos en la sociedad, particularmente en algunas partes del campo. Estos cambios han contribuido a legitimar el cambio de régimen entre amplios sectores de la población — particularmente en la zona rural del Sur-. Existe lugar para el descontento entre los desempleados y particularmente entre los trabajadores agrícolas, siendo también a este respecto el campo español más comparable al de otros países de la Europa Occidental, donde los propietarios agrícolas se encuentran atrapados en el resquicio entre los precios industriales y los agrícolas.

Se podría decir que la democracia española podría seguir muy bien el camino de la democracia italiana. La estructura social de los dos países presenta muchas afinidades, y ambos, aunque han alcanzado un relativamente elevado nivel de industrialización, están todavía lejos de la era postindustrial. En ambos países existen importantes regiones que sufren subdesarrollo económico, presión de población y las consecuencias de una distribución de la riqueza injusta —aun cuando en el caso de España el problema está menos concentrado en una sola región, como en el Mezzogiorno italiano, y la desintegración social no ha alcanzado los mismos niveles que en Italia-, con su clientelismo, la Mafia, y la presencia significativa del neofascismo en el Sur. El electorado español comenzó su curso con una mayor fuerza en la izquierda de lo que lo hizo en Italia en 1946. Sin embargo, el Partido Comunista español ha sido más débil, consiguiendo solamente el 9,3 por 100 de los votos, comparado con el 18,9 por 100 conseguido en Italia, y todavía tiene un largo camino que recorrer antes de que lleguen al 34,4 por 100 conseguido por el PCI en 1976. ¿Conseguirán los socialistas españoles mantener su posición dominante sobre la izquierda (con un 29,4 por 100 de los votos), o seguirán el curso de los socialistas italianos que comenzaron en 1946 con el 20,7 por 100 y terminaron con el 9,6 por 100 para el PSI y 3,4 por 100 para el PSDI en 1976? Parece dudoso que la UCD pueda nunca conseguir el triunfo extraordinario de la DC italiana en 1948 (con el 48,5 por 100 de los votos) y ni siquiera mantener hasta el 38,7 por 100 que todavía tiene después de treinta años en el poder, y como dirían muchos italianos, de mala administración.

La diferencia esencial entre el sistema de partidos italiano y el español radica en la ausencia de un partido Demócrata Cristiano, con todo lo que esto implica —el afianzamiento de lealtades de partido en una subcultura religiosa; la disponibilidad, en cada parroquia, de una red de dirigentes y activistas; el apoyo de asociaciones profesionales orientadas religiosamente; el apoyo más o menos explícito o indirecto de la Iglesia; la base ideológica en un sistema de ideas flexible capaz de cercar las progresivas ideas izquierdistas (así como el pensamiento conservador) y los fuertes lazos internacionales que han hecho de los Partidos Demócrata Cristianos líderes activos en el proceso de unificación europea-. No es lo mismo, obviamente, construir un partido sin estas estructuras de apoyo, y mucho menos en una época en la 
que la guerra fría se ha «enfriado» y en la que es más difícil articular un anticomunismo contra un partido eurocomunista.

La UCD fue constituida mediante la transformación de una coalición electoral en un partido unificado, abarcando diferentes tensiones ideológicas y diferentes personalidades, algunas de las cuales aceptarían sólo a medias el liderazgo del Primer Ministro Suárez, cuya influencia les podía asegurar un escaño. Los hombres de UCD comparten muchas cosas, particularmente sus intereses como una clase política, su posición social, su educación y estilo de vida; pero sus biografías políticas durante el régimen de Franco son bastante diferentes. Algunos estaban en la oposición, mientras que otros fueron gobernadores provinciales de Franco. Las tensiones producidas por estas diferencias parece que están siendo superadas, pero la UCD nunca tendrá una estructura compartida de referencia ni todas las conexiones interpersonales que han sido la base de los Cristianodemócratas. Es difícil construir un partido interclasista sin la base religiosa, y a pesar de los grandes esfuerzos para situarlo en el centro-izquierda y de abandonar las posiciones conservadoras de muchos líderes del partido, la UCD se parece más a un moderno partido conservador, como los partidos franceses a la derecha de los socialistas, que a uno Demócrata Cristiano. Por otro lado, como en una sociedad cada vez más secular no está ligado o identificado con la Iglesia, enfrenta a muchas personas y puede ser más flexible en lo que respecta a muchas materias que, de hecho, atan a la Iglesia a los demócrata cristianos en Italia. A pesar de la presencia de demócratas cristianos y miembros del Opus Dei en sus filas, el carácter secular de la UCD es una ventaja para el sistema político español, donde los conflictos de base religiosa contribuyeron tanto a la crisis y caída de la Segunda República.

Otra cuestión diferente se refiere a la capacidad de UCD de penetrar en regiones con una tradición autonomista - Cataluña y el País Vasco- y, por tanto, de servir como un partido nacional de integración de centroderecha. Este ha sido un problema al que la Democracia Cristiana italiana no se ha tenido que enfrentar. Por otro lado, la UCD no está flanqueada, si dejamos aparte al catalanista Pacte Democratic per Catalunya, por partidos menores como el Social Demócrata italiano PSDI, los Republicanos e incluso los Liberales, que contribuyeron con sus líderes y miembros más importantes a la formación de gobiernos de coalición hasta que se agotó esta fórmula; posteriormente, cuando se redujeron a un 15 por 100 los votantes del partido, ocupó su lugar la «apertura a sinistra» con la inclusión del Partito Socialista Italiano (PSI). En España se menciona a menudo la idea de una coalición entre la UCD y el PSOE, que sería bien recibida incluso por una parte del electorado; pero aquellos que lo sugieren ignoran los hechos básicos hasta la próxima elección. Tal coalición representaría electoralmente un 64,23 por 100 del electorado y tendría 291 escaños de los 350 existentes, lo que sería contrario a la idea de la coalición ganadora mínima, que ence- 
rraría posiciones extremadamente heterogéneas; ignoran la relativa fuerza del PSOE y su ambición de llegar a ser una alternativa de gobierno -la «alternativa democrática» que constantemente es proclamada por Felipe González como una baza de su partido-. Desde mi punto de vista, tal coalición, excepto en el caso de una situación de crisis extrema, haría vulnerable a los dos partidos a la atracción de sus competidores, el PCE y AP, cuando no a una seria crisis interna que podría llevarles a su ruptura y, más aún y rápidamente, a la fragmentación del sistema de partidos. El sistema de partidos español, como el italiano, tiende a hacer del partido de centro (la UCD y quizá más adelante, si se mueve en la dirección de la Social Democracia, un PSOE de Centro-Izquierda) la única fuerza que puede gobernar; al mismo tiempo, esto hace que le sea muy difícil al partido del centro entrar en alianzas que le asegurarían una cómoda mayoría parlamentaria, pero que también polarizarían al país. El sistema de partidos español impone un gobierno minoritario que únicamente puede mantenerse sólo gracias a la tolerancia parlamentaria de uno o más partidos de la oposición y a la cooperación de partidos menores; en el caso español, los partidos regionalistas, los cuales pueden exigir, a cambio de su apoyo, un alto precio. No compartimos el punto de vista de algunos analistas que, olvidándose de los partidos en los extremos del espectro, piensan que el sistema español permitiría el surgimiento de un sistema bipartidista limitado, basado alternativamente en el PSOE y la UCD. Además, constantemente, la heteroge. neidad interna de la UCD estimula las esperanzas por parte del PSOE de que algunos diputados de la UCD pudiesen apartarse del liderazgo de Suárez y ayudar al PSOE a alcanzar el poder, puede que con el apoyo de los partidos regionales. Esta esperanza es, en sí misma, un obstáculo para la institucionalización del Gobierno y para una lealtad responsable de la oposición y anima las tendencias hacia el esquema italiano - partidos que sobreviven en el poder sin gobernar y que comparten el poder sin compartir la responsabilidad-, tan bien descrito por Giuseppe di Palma. El deseo de conseguir un amplio consenso para evitar confrontaciones abiertas y públicas entre el Gobierno y la oposición, la utilización de estratagemas transformadoras, la combinación de la oposición en los procesos electorales y en las calles, y la cooperación en el Parlamento que caracteriza la reciente política italiana, tienen algún paralelo en España.

El Pacto de la Moncloa y los acuerdos entre todos los partidos se tomaron en el sentido de poder enfrentarse a los problemas económicos durante el período de transición y para instituir algunas políticas básicas sobre el consenso, aun cuando Suárez ha hecho claro que puede no ser éste el esquema después de la aprobación de la Constitución. Existen, sin embargo, fuertes presiones, heredadas del período franquista, para una política cercada y para una ideología que es congruente también con la concepción católica de la «bonum comune», que deslegitima la defensa egoísta del interés que 
caracteriza a la democracia pluralista anglosajona. Encajan muy bien en este modelo algunas de las diferencias entre la concepción de la democracia de los MP británicos y los diputados italianos, descubierta por Robert Putnam ${ }^{20}$. Obviamente, como demuestra la experiencia italiana, la lucha de los intereses políticos continúa bajo cuerda, pero sin legitimidad pública.

Finalmente, existe una pequeña, pero no menos importante, diferencia entre la política española e italiana: la relativa fuerza de los partidos a la izquierda de los comunistas. En España, dichos partidos fueron capaces de conseguir el 3,05 por 100 de los votos en las elecciones de junio de 1978, mientras que en Italia obtuvieron el 2,8 por 100 . En una provincia, Navarra, esos partidos consiguieron el 9,6 por 100 de los votos. El mayor número de votos locales conseguidos en Italia fue del 3,5 por 100 en una ciudad. Estos datos se vuelven más significativos si comparamos el 2,8 por 100 de los partidos de la extrema izquierda y el 34,4 por 100 de los comunistas en Italia, con el 3,05 por 100 y el 9,2 por 100 , respectivamente, en España Aunque el PCE ignora totalmente la competición a su izquierda, no podemos dejar de mencionarla como una de las diferencias con la situación italiana.

Hasta ahora, la democracia española tiene la ventaja de no enfrentarse a un partido neofascista como el Movimento Sociale Italiano, que consiguió un 6 por 100 de los votos en 1976 y que mantiene lazos con los «groupuscules» extremistas, porque Fuerza Nueva, que está ligada estrechamente con la violencia de la extrema derecha, y otros grupos radicales de derecha, solamente consiguieron obtener un 0,61 por 100 de los votos en 1977. AP, bajo el liderazgo de Fraga, no quiere moverse en esa dirección claramente, aunque algunos de sus votantes estén tentados de hacerlo si se produjera una polarización de la sociedad española. En algunos aspectos se podría decir que el sistema de partidos italiano está más fragmentado que el español, desdeñando por el momento la presencia de las autonomías regionales $y$ de los partidos nacionalistas en España.

Hay tendencias en el sistema de partido español que podrían conseguir desarrollos similares a aquellos posibles en Francia, es decir, la gran coalición de la izquierda basada en un programa común. Desde luego, los recelos de los socialistas hacia los comunistas, su propia imagen como el partido dominante de la izquierda, la falta de interés del PCE de realizar muchos cambios durante el período de consolidación de la democracia y su desconfianza de la juventud y dirección más ideológica del PSOE hace que tal desarrollo sea poco factible en un futuro próximo. Por otro lado, la posición eurocomunista de Carrillo hace que el PCE sea un partido mucho más elegible para la política democrática que el PCF. Sin embargo, los

20 Robert D. Putnam, The Beliefs of Politicians: Ideology, Conflict and Democracy in Britain and Italy (Yale University Press, New Haven, Conn., 1973). 
orígenes históricos y el desarrollo de la UCD y de AP, a pesar de haber muchos puntos de contacto, hacen más difícil que en Francia la cooperación entre todos los partidos burgueses de la derecha. Una elección bipolar, como la elección francesa de 1978 , crearía tensiones extremadamente serias para la nueva democracia española.

La transición griega hacia la democracia en 1974 está en algunos aspectos entre el modelo español y portugués ${ }^{21}$. El proceso que condujo a un Gobierno civil bajo Karamanlis y a la proclamación de elecciones libres no fue un proceso reformista iniciado de forma ordenada bajo el régimen de los coroneles, sino que, por el contrario, fue impuesto por la amenaza de un golpe militar del tercer ejército, y siguió a este respecto un desarrollo parecido al portugués, pero, lejos de llevar a los militares a un «Machtergreifung», condujo al presidente, el general Gizikis, mediante un llamamiento militarcivil, a darle el poder al líder de un partido en el exilio. Existían, por tanto, algunos elementos de continuidad con un régimen autoritario cuyas características eran bastante diferentes del que había en España. La transmisión del poder fue el resultado de una crisis insoluble creada por Grecia y el régimen de Ionnidis por el desastre de Chipre después de la intervención griega contra Makarios y la invasión turca que siguió. En este aspecto, el caso griego es similar al portugués: los sucesos exteriores irrumpen en el país y en las fuerzas armadas y provocan una crisis en el régimen que se resuelve rápida e inesperadamente mediante la transición a la democracia. Sin embargo, difiere fundamentalmente de la situación portuguesa, ya que no se creó una crisis revolucionaria o semirrevolucionaria ni provocó una subida al poder de la izquierda; se transfirió el poder al líder de la Unión Radical Nacional, Ethniki Risopastiki Enosis (ERE), un partido y un líder que ocupó el puesto de primer ministro (1955-1963) antes del golpe del 21 de abril de 1967. La duración del Gobierno militar (menor que la de un presidente francés), el hecho de que no subiera al poder debido a una polarización de la sociedad, ni por la movilización de las masas en un movimiento antidemocrático, sino mediante un bien planeado golpe llevado a cabo por un pequeño grupo de conspiradores aceptados por el rey y reconocidos internacionalmente, que demostró ser incapaz de institucionalizarse y que tuvo muy poco éxito al elegir a los líderes políticos civiles, y que sufrió una serie de crisis inter-

"Sobre la democracia griega, la dictadura y la transición, véanse Keith $\mathrm{R}$. Legg, Political Change in a Clientelistic Polity: The Failure of Democracy en Greece, en "Journal of Political and Military Sociology", I (final 1973), pp. 231246; Nicos Mouzelis, Capitalism and Dictatorship in Post-War Greece, en "New Left Review", 96 (marzo-abril 1976): 57-80; Richard Clogg y George Yannopoulos (eds.), Greece Under Military Rule (Basic Books, New York, 1972); "Ateniense" (pseudónimo de Rodis Rophons), Inside the Colonel's Greece (Chatto \& Windus, Londres, 1972); Marios Nikolinakos, Widerstand un Opposition in Griechenland: Vom Militarputsch 1967 Zur Neuen Demokratie (Hermann Luchterland, Darmstadt, 1974), y Jean Maynaud, Rapport sur l'abolition de la Démocratie en Grèce (Meynaud, Montreal, 1970). 
nas que condujeron al desplazamiento de Papadopoulos en un golpe de noviembre de 1973, nos permite hablar de una restauración de la democracia en vez de la instalación de un nuevo régimen. Sin embargo, en los años que van desde el golpe de 1967 a 1974, muchas cosas han cambiado en Grecia. La monarquía ha contribuido decisivamente a la crisis de la democracia parlamentaria durante el período que precedió al golpe; ha alienado a la clase política al permitir que Papadopoulos utilizara la autoridad del rey; posteriormente intentó desplazar a los coroneles mediante un golpe mal planeado que condujo al exilio del rey y, más adelante, a la derogación de la monarquía por la Junta. A pesar de algunos sentimientos monárquicos de la Marina, que se plasmaron inclusive en motines contra la dictadura militar, Karamanlis no reestableció la monarquía. Poco después de su éxito parlamentario obtuvo en un referéndum un 70 por 100 de los votos a favor de la República. Karamanlis se encontró, en la nueva democracia, en una posición más fuerte que la de Suárez; como un líder que sufrió el exilio y la hostilidad de los coroneles, no se encontró entre la clase política con el tipo de respuesta ambivalente como a la que tuvo que enfrentarse Suárez.

La corta dictadura, con su política represiva, con el terror y las torturas, con su anticuado estilo, sus fallos en política exterior y con la amplia imagen que dio de ser un instrumento, cuando no un producto, de los intereses extranjeros, afectó a distinguidas personalidades de la vida griega -incluyendo a los políticos moderados-. Levantó una profunda hostilidad que, actualmente, hace de la revisión del pasado un recuerdo vivo. Por el contrario, también creó un cierto grado de convergencia entre una importante facción de la clase política y dio lugar a activas protestas masivas - particularmente entre los estudiantes de la Universidad Técnica-, que dieron lugar a acciones represivas en una escala que no se dio en la Portugal metropolitana bajo Salazar y Caetano.

La historia política de Grecia le dejó a la democracia un cierto número de complicados legados. Aun cuando los conflictos regionales, debido a la ausencia de las aspiraciones autonomistas y separatistas, no tienen la misma intensidad que en España, el país se enfrenta a problemas mayores como son los dilemas de la política exterior debido al caso de Chipre, el heredado conflicto histórico con los turcos y las disputas que están irrumpiendo acerca del Egeo y sus recursos petrolíferos. Contribuyeron al fraccionamiento político, la confrontación entre Venizelos y el rey, la sucesión de la monarquía-república y la dictadura de Metaxas antes de la guerra. Y la más importante $y$ todavía resonante división fue la producida por el intento comunista de subir al poder (1944) y la consiguiente guerra civil (1946-1949); una vez más en la larga historia de Grecia, las alianzas extranjeras - primero con Inglaterra y posteriormente con los Estados Unidos- fueron decisivas para la consolidación de la monarquía. El intento comunista dejó una herencia amarga y tuvo que ver con el anticomunismo radical de las fuerzas 
Porcentajes de votos y números de escaños obtenidos por los diferentes partidos en las últimas elecciones en el sur de Europa

\begin{tabular}{|c|c|c|c|c|c|c|}
\hline $\begin{array}{l}\text { Tendencia } \\
\text { ideológica }\end{array}$ & $\begin{array}{c}\text { ITALIA, } \\
\text { junio } 1976\end{array}$ & $\begin{array}{c}\text { GRECIA, } \\
\text { noviembre } 1977\end{array}$ & $\begin{array}{l}\text { PoRTUGAL, } \\
\text { mayo } 1976\end{array}$ & $\begin{array}{c}\text { ESPAÑA, } \\
\text { junio } 1977\end{array}$ & \multicolumn{2}{|c|}{$\begin{array}{c}\text { FRANCIA, } \\
\text { marzo } 1978\end{array}$} \\
\hline $\begin{array}{l}\text { Extrema } \\
\text { izquierda }\end{array}$ & $\mathrm{DP}(1,5)$ & -- & $\begin{array}{l}\text { Ocho partidos } \\
(4,8)\end{array}$ & $\begin{array}{l}\text { FDI (PTE) } \\
(1,46) \\
\text { AET (ORT) } \\
(0,44) \\
\text { Otros }(1,15) \\
\text { Total }(3,05)\end{array}$ & $\begin{array}{c}\left(1 .^{2} \text { vueita }\right) \\
(3,3)\end{array}$ & - - \\
\hline Comunistas & PCI $(34,4)$ & $\begin{array}{ll}\text { KKE (Ex) } & \\
\quad(9,3) & 11 \\
\text { Partido C. del } & \\
\quad \text { interior }(2,7) & 2\end{array}$ & PPC $(14,6)$ & $\begin{array}{c}\text { PCE-PSUC } \\
(1,28)\end{array}$ & PCF $(20,6)$ & 86 \\
\hline Socialistas & PSI $(9,6)$ & $\begin{array}{c}\text { PASOK } \\
(25,3)\end{array}$ & PS $(35,0)$ & $\begin{array}{l}\text { PSP (US) } \\
\quad(4,49) \\
\text { PSOF }(29,38)\end{array}$ & PS $(22,6)$ & 103 \\
\hline $\begin{array}{l}\text { Otros de } \\
\text { izquierdas } \\
\text { Centro- } \\
\text { izquierda }\end{array}$ & $\begin{array}{l}\text { PR }(1,1) \\
\text { PSDI }(3,4) \\
\text { PRI }(3,1)\end{array}$ & -- & PPD $(24,0)$ & ASD $(0,75)$ & MRG $((2,1)$ & 10 \\
\hline
\end{tabular}




\begin{tabular}{|c|c|c|c|c|c|c|c|c|c|}
\hline $\begin{array}{l}\text { Partidos } \\
\text { regionales }\end{array}$ & $\begin{array}{l}\text { Svp }(0,5) \\
\text { Valle } \\
\text { d'Aosta }(0,2)\end{array}$ & -- & -- & -- & -- & $\begin{array}{l}\text { EE }(0,34) \\
\text { PNV }(1,70) \\
\text { EC }(0,74) \\
\text { PDC }(3,73) \\
\text { UDC-CC } \\
(0,92) \\
\text { P. gallegos } \\
(0,28)\end{array}$ & $\begin{array}{r}1 \\
8 \\
1 \\
11 \\
2 \\
--\end{array}$ & -- & -- \\
\hline $\begin{array}{l}\text { Centro- } \\
\text { Cristiano } \\
\text { Demócratas }\end{array}$ & DC $(38,7)$ & -- & -- & $\operatorname{CDS}(15,9)$ & 41 & $\operatorname{FDC}(1,41)$ & -- & -- & -- \\
\hline Otros & -- & $\begin{array}{l}\text { Unión Centro } \\
(12,0) \\
\text { Neo-Democra- } \\
\text { cia }(41,9)\end{array}$ & $\begin{array}{r}15 \\
172\end{array}$ & - & -- & UCD $(34,8)$ & 167 & $\begin{array}{l}\text { Soutien du } \\
\text { Pres. Rep. } \\
(2,4) \\
\text { UDF }(21,5)\end{array}$ & $\begin{array}{r}4 \\
137\end{array}$ \\
\hline Derecha & PLI $(1,3)$ & -- & -- & PPM $(0,5)$ & -- & AP $(8,4)$ & 16 & $\operatorname{RPR}(22,6)$ & 148 \\
\hline Otros partidos & -- & -- & -- & -- & -- & -- & -- & $\begin{array}{l}\text { Ecologis. } \\
\quad(2,1) \\
\text { Otros }(1,2)\end{array}$ & -- \\
\hline $\begin{array}{l}\text { Total, } 100 \% \mathrm{de} \\
\text { votos }\end{array}$ & 629 & & 300 & & 259 & & 350 & & 491 \\
\hline
\end{tabular}


armadas, que fue uno de los factores del golpe de 1967. Los resultados de la política exterior ocupan un lugar central en el debate político más que en ningún otro país mediterráneo. Toda la historia de la independencia de Grecia ha creado una conciencia acerca de la importancia de las alianzas internacionales en la política interna. La puja comunista por el poder, apoyada desde el extranjero y derrotada con la ayuda occidental, la asociación de la economía griega con sus actividades comerciales y marítimas y la debilidad de la clase empresarial industrial y nacional — junto con la importancia de la emigración de sus trabajadores a los países del Mercado Común-, han hecho central para la izquierda el tema del subdesarrollo y de la dependencia. La verdadera o supuesta intervención de la CIA, las relaciones entre los Estados Unidos y la Junta y las complejidades de la política americana y europea en relación con los dos aliados enemigos - Grecia y Turquíaacerca de la cuestión de Chipre, hacen que sean más controvertidos los resultados de las relaciones con la NATO y con la CEE que los de la Península Ibérica. A pesar de los esfuerzos gubernamentales para luchar contra la izquierda en su propio juego político externo, Andreas Papandreou y su Movimiento Socialista Panhelénico (PASOK) han sido capaces de capitalizar una posición supranacionalista y una tendencia a identificar a los enemigos externos como la fuente de los males y de las desgracias del pueblo. Como uno de los partidos principales de la oposición, el PASOK ha introducido un estilo político, un nuevo grupo de personal político (de sus 93 diputados, 73 fueron elegidos por primera vez en 1977) y una atracción basada en las injusticias sociales y económicas populares; aunque el interés de Papandreau difiere del de aquellos partidos de antes de 1967 -incluyendo a la Unión del Centro, dirigida por su padre, Jorge Papandreou.

La Neo-Democracia, que en 1974 obtuvo el 54,4 por 100 de los votos y 220 escaños de los 300 existentes, ha gobernado, por tanto, sola (aunque aceptó formar una coalición con la Unión del Centro de Mavros), vio su apoyo reducido al 41,9 por 100 de los votos y a 172 escaños en 1977, mientras que el PASOK aumentó su participación del 13,6 por 100 al $25,3 \mathrm{y}$, gracias a la ley electoral que favorece a los partidos mayores, de 12 a 93 escaños. En vista de las dificultades que Karamanlis se puede encontrar en temas de política exterior y de economía, la importante pérdida de su aliado Mavros y la ausencia de pequeños partidos amortiguadores, la posibilidad de una alternancia entre la derecha y la izquierda no debe de excluirse. Por otro lado, existen elementos de polarización en el sistema político griego: primero, la presencia y el éxito del Partido Comunista de Grecia, un partido promoscovita que obtuvo el 9,36 por 100 de los votos (comparado con el 2,72 por 100 del Partido Comunista del Interior -en alianza con otros cuatro partidos menores-, que defendían una posición eurocomunista, y del 9,45 por 100 de la Izquierda Unida - EA - en la elección anterior); y segundo, los intereses simultáneos del Frente Nacional, el 
partido de extrema derecha identificado con el régimen anterior, que consiguió pasar del 1,10 por 100 de los votos al 6,82 por 100 . A pesar de que el sistema electoral es altamente desigual, evita que los partidos de los extremos jueguen el papel que les asigna Satori en sistemas multipartidistas, polarizados y centrífugos, las distribuciones y tendencias electorales apuntan en esa dirección ${ }^{22}$.

La dictadura, al suspender la actividad política y romper los lazos establecidos, ha conducido a un nuevo esquema - la competición de un partido conservador cuyo apoyo electoral depende, en parte, de los tradicionales esquemas clientelísticos con un partido popular de masas que se llama a sí mismo Socialista, que rechaza el modelo de la Social Democracia europea occidental y del Norte que interpreta la situación griega de un modo sui generis desde una perspectiva nacionalista-. La última postura anti-NATO $\mathrm{y}$ anti-CEE (que invoca un tipo de conexión más noruego con el Mercado) está combinada con un programa de reforma social y los beneficios para la personas más modestas de la ciudad y del campo para evitar las ventajas de los grupos económicamente privilegiados y de los capitalistas extranjeros. La confrontación entre estas alternativas conservadoras y socialistas, dirigida por dos líderes fuertes en la volátil situación internacional de Grecia y a la sombra de las fuerzas armadas, es bastante diferente de la compleja política del consenso en Italia (que algunos llamarían «consociacional») y de los esfuerzos de Suárez para alcanzar un consenso más amplio - por lo menos en el proceso de realización de la Constitución- y de enfrentarse a la crisis económica con los acuerdos de la Moncloa.

\section{Socialismo mediterráneo: ¿una alternativa a la social-democracia?}

Uno de los elementos distintivos en la política de los países mediterráneos es la fuerte tendencia hacia el tema del modelo de sociedad y política de la social-democracia y el desarrollo de la idea de que los partidos del sur de Europa podrían ofrecer una alternativa interesante que estaría más cerca del verdadero socialismo. En muchos mítines de los militantes del PSOE, el canto «La social-democracia no nos hace gracia» expresa exactamente este sentimiento. A comienzos de 1977, los españoles se enfrentaron con las alternativas ideológicas de la «social-democracia» y del «socialismo», en una lista que también incluía al liberalismo. La democracia cristiana, el comunismo y demás eligieron una de las dos — probablemente atribuyéndole significados muy imprecisos a las palabras; su particular elección, significativamente) correlacionaba bien con actitudes muy distintas hacia muchos pro-

"2 Nicos Mouzelis, On the Greek Elections, en "New Left Review", 108 (marzoabril 1978): 59-74. 
blemas-. El PSOE consiguió votos de ambos sectores de la opinión, aun cuando un ala de la UCD se llama a sí misma social-democrática y ha sido capaz de obtener algunos votos entre aquellos que se identificaban con la alternativa ideológica. Sin embargo, los activistas del PSOE tienden a rechazar a la social-democracia, y el término ha adquirido un significado peyorativo; los líderes del partido son mucho menos explícitos en su postura, aunque los más estudiosos evitan el término.

Los partidos socialistas mediterráneos se definen a ellos mismos como marxistas, aunque recientemente Felipe González, quizás como un reflejo del abandono del leninismo por parte del PCE, levantó la polémica sobre si sería deseable retirar el compromiso del marxismo en el programa del partido sin cuestionar la obvia contribución marxista al socialismo. Los diferentes puntos de vista de los socialistas del Sur fueron articulados muy claramente por los partidos no afiliados a la Internacional Socialista; pero incluso entre los últimos apareció una hendidura clara sobre ciertas posiciones entre dos bloques diferenciados: un bloque norte, bajo el liderazgo del Partido Laborista y del SPD, y un bloque sur, centrado en el PSF y el PSOE (presumiblemente sobre las bases de su superior fuerza comparados con el PSI italiano). En 1975 y en 1976, en varias reuniones, particularmente en Elsinore, se hizo aparente la diferencia entre los dos bloques. La consecuencia principal y más inmediata fue la postura hacia el Partido Comunista, un resultado central para el Programa Común de Mitterrand y para sus esperanzas de un Gobierno de izquierdas en Francia. La presencia en todos los países de la zona de fuertes Partidos Comunistas hacen centrar ese resultado. Alfonso Guerra, miembro de la Ejecutiva del PSOE y amigo personal de Felipe González, lo formuló: «Desde que los Partidos Socialistas han elegido una estrategia de ruptura y los Partidos Comunistas afirman su autonomía política, existe la posibilidad de la unidad sin que ninguno de los partidos sea hegemónico... Para dejar de lado la competencia irracional, las campañas antisocialistas de algunos Partidos Comunistas y el anticomunismo de algunos socialistas que no favorecen a nadie más que a la derecha en el poder. Los socialistas y los comunistas deben tomar conciencia de su tarea en común y actuar de acuerdo» ${ }^{23}$.

Se manifestó la esperanza de que las nuevas condiciones políticas en el sur de Europa pudiesen modificar el punto de vista político mundial. Como apuntó Guerra: «La influencia americana en Europa y las políticas de defensa (NATO contra Pacto de Varsovia) pueden romperse mediante la presencia política, en los países del sur de Europa, de las fuerzas progresivas en el poder» ${ }^{24}$. Se podría añadir a las diferencias ideológicas entre los par-

23 Alfonso Guerra, Los partidos socialistas del sur de Europa y las relaciones socialistas-comunistas, una publicación especial sobre "Problemas actuales del socialismo español", en Sistema, 15 (octubre 1976): 53-60.

${ }^{24}$ A. Guerra, Los partidos socialistas del sur de Europa, p. 56. 
tidos las tensiones naturales derivadas de la relación Norte-Sur, entre los países menos desarrollados económicamente y entre las naciones industrializadas más ricas de Europa — países de emigración y receptores de «Gastarbeiter», entre países en los que las inversiones extranjeras provienen de los países capitalistas avanzados y países inversores-. Esta relación desigual ha conducido a estos países a un cierto grado de identificación con el Tercer Mundo, lo que se manifiesta en una simpatía hacia la OLP y en la ayuda al Frente Polisario. La posición neutralista del PSOE se refleja en su buena disposición acerca de la cuestión de la entrada de España en la OTAN, pero no en la CEE y en su deseo de mantener contactos con los dirigentes de los países y Partidos Comunistas, algunos de los cuales enviaron delegados al Congreso del PSOE.

Un socialismo mediterráneo aún más explícito llevó a la celebración de dos conferencias, una en Barcelona en noviembre de 1976 y la otra en Malta en junio de 1977; se convocó una tercera para 1979 en Atenas. Estas conferencias animaron a la unión de los partidos tanto del lado europeo como del lado árabe del Mediterráneo y a manifestar su independencia de, y su oposición a, la Internacional Socialista por ser considerada demasiado eurocéntrica, demasiado pro-israelí y dominada por los social-demócratas del norte de Europa. Esto proporcionó a los árabes la oportunidad de expresar sus puntos de vista acerca del Próximo Oriente y de encontrar esquemas de entendimiento en Europa, y le dio a todos los partidos la oportunidad de centrar la atención en el Mediterráneo y de denunciar la intervención de poderes externos a la zona, así como de conseguir apoyo para su propio interés nacional y para su causa política y acumular algún capital para su propio uso. Esta última consideración fue muy importante para el Partido Socialista Popular (PSP) y para la Federación de Partidos Socialistas (FPS) en relación con su oposición al PSOE. La conferencia de Barcelona fue organizada, con financiación libia, por estos dos partidos: el Partido Laborista de Malta y el Congreso General del Pueblo de Libia; participaron el PASOK, EDEK de Chipre, el Partido Argelino y la OLP. En Malta, en la segunda conferencia, asistieron los Partidos Socialistas español, maltés, francés e italiano; el PCI, la Alianza Socialista de Yugoslavia y un cierto número de socialistas árabes, aunque en calidad de observadores. Las naturales diferencias de los puntos de vista entre los diferentes partidos — que oscilaron desde la unión de la religión y el socialismo de los libaneses al común rechazo de Papandreou por parte de los europeos, pasando por aquellos que defendían el que las conferencias mediterráneas estuviesen relacionadas con los diálogos Norte-Sur y europeo-árabes- no dejaron lugar para muchos acuerdos. En Malta, los puntos de acuerdo principales fueron: el apoyo a los palestinos, la integridad territorial y la integridad de Chipre, la neutralidad y no alineación de Malta y el apoyo para los movimientos de liberación como el Polisario. 
Sería interesante conocer cuál sería la influencia que sería capaz de ejercer el anterior líder del PSP, ahora fusionado con el PSOE, en la dirección de un socialismo mediterráneo. Pero incluso, independientemente de la cooperación entre los partidos, existen diferencias insalvables entre los puntos de vista de los socialistas del Norte y del Sur, aun cuando existan alas social-demócratas en el Sur y tendencias izquierdistas y marxistas en el Norte, que proporcionan otras bases ideológicas y quizás algo más que ideológicas. Por otro lado, no podemos olvidar los fuertes lazos establecidos entre los Partidos Socialistas principales de la Península Ibérica y la Internacional Socialista y particularmente con el SDP; estas asociaciones cuentan declaradamente con importante ayuda financiera. La consideración sobre qué tipo de significación política práctica tendrían las posiciones ideológicas divergentes si algunos de estos partidos llegase al poder es otra cuestión.

\section{Comunismo en Europa del Sur}

No se puede hablar con propiedad de la existencia de un comunismo mediterráneo, ya que los partidos de la zona oscilan entre la orientación promoscovita, como la del Partido de Grecia (refiriéndonos al mayor de los dos que compiten en aquel país); el PCP, que intentó conseguir el poder ayudando a las facciones revolucionarias del MFA, y el PCI y PCE, que se han convertido en los representantes principales del eurocomunismo. Si exceptuamos al PC francés, al finlandés, a la Alianza de la Gente de Islandia, dominada por los comunistas, y al Partido Luxemburgués, ninguno de los partidos de la Europa Occidental han logrado una fuerza semejante ${ }^{25}$. Si contabilizamos la parte total de votos conseguidos en las elecciones parlamentarias más recientes por los cuatro países del Sur, obtenemos un 24 por 100, en contraste con el 10,3 por 100 contabilizado en 1973 por los Nueve, incluyendo a Italia. Lo que es más importante es que el PCI es un partido con vocación gubernamental y que en Italia desde 1977 está gobernando la Democracia Cristiana - gracias al «acuerdo programático» por el que el Partido Comunista Italiano participaba con todos los otros principales partidos y, más recientemente, gracias a la fórmula del «governi di non-sfiducia»La teoría de un PCI dentro del Gobierno, bajo la fórmula del «compromesso storico", ha abierto un debate internacional, político e intelectual donde las posiciones varían desde una expectación esperanzada hasta unas predicciones desastrosas.

La creciente utilización del término eurocomunismo y su aceptación por parte de algunos dirigentes comunistas representa un cambio decisivo e in1975).

25. Neil McInnes, The communist parties of western Europe (Oxford, Londres, 
troduce una nueva variante sobre el comunismo ${ }^{26}$. Desde la perspectiva de los políticos de Estados Unidos y de otros anticomunistas, son centrales las cuestiones sobre si dichos partidos deberían o no estar en la escena internacional, las relaciones entre ellos y entre estos partidos y Moscú y el impacto del eurocomunismo en la Europa Oriental. La cuestión prioritaria consiste en definir al eurocomunismo y qué partidos deben ser considerados dentro de esa tendencia. A pesar de las reuniones y de las declaraciones del PCI, PCE y PCF, parece haber grandes diferencias de estilos y en las tácticas de esos partidos, especialmente de los dos primeros con el PCF. Por ser el PCI el máximo exponente de un tipo diferente de comunismo, seguido de cerca por el PCE, ha absorbido la atención de los políticos científicos y de los sociólogos ${ }^{27}$. Leemos artículos con el título de "Compromesso Storico y Democracia Consociacional: Hacia una "Nueva Democracia"», que analizan la «colaboración antagonista» (la cual es también descrita como una "convergencia a través de la hegemonía») que salvaría a la democracia italiana del callejón sin salida en el que se encuentra en la actualidad. Otros analistas describen cuidadosamente el escenario, en varias etapas, de lo que pasaría después de la entrada del PCI en el Gobierno. Ahondando en el pasado de todos estos debates, nos encontramos con la experiencia de la Unidad Popular y el golpe contra Allende en Chile ${ }^{28}$, con los recientes intentos de los comunistas griegos de tomar el poder, con la reciente actitud del Partido Comunista Portugués (el cual no se parecía a otros de los partidos comunistas de la Europa Occidental durante el crítico año de 1975) y la alternativa del ahora difunto Programa Común, que, presumiblemente, fue una alternativa de la izquierda con la participación comunista, pero que permaneció bajo la dirección de los socialistas. Los dirigentes comunistas de Italia y España están analizando la situación desde una más ancha pers-

2h Giuseppe di Palma, ¿Eurocommunism?, artículo de la revista "Comparative Politics", 9 (abril 1977): 357-375; Kevin Delvin, The Challenge of Eurocommunism, en "Problems of Communism", 26 (enero-febrero 1977): 1-20; Manfred Steinkühler, Eurocommunism: Myth and Reality, en "Aussenpolitik", 28 (último cuarto de 1977): 375-403. Para un punto de vista de la izquierda, véase André Gunder Frank, Eurocommunism: Left and Right Variants, en "New Left Review", 108 (marzo-abril 1978): 88-92. Santiago Cairillo, Eurocomunismo y Estado. El "eurocomunismo" como el modelo revolucionario idóneo en los países capitalistas desarrollados (Crítica, Barcelona, 1977), representa la contribución española y debe leerse junto con los documentos del Noveno Congreso del 19 de abril de 1978 . recogido en Mundo Obrero y Nuestra Bandera. Para una compilación de documentos eurocomunistas anteriores, véanse Mariangela Bosi y Hugues Portelli, Les P.C. espagnol, français et italien face au pouvoir (Christian Bourgeois, París, 1976).

${ }^{27}$ Véanse Donald L. M. Blackner y Sidney Tarrow (eds.), Communism in Italy and France (Princeton University Press, Princeton, 1975); para una excelente compilación de ensayos y mayores referencias, véase también Gianfranco Pasquino, El PCI: A Party with a Governmental Vocation, en "Occasional Paper", 19, Research Institute of the John Hopkins University (Bologna Center, 1987).

${ }^{28}$ Enrico Berlinguer, Reflessioni Sull-Italia Dopo $i$ Fatti del Cile, en "Rinascita" (28 septiembre, 5 y 12 octubre 1973). 
pectiva comparativo-histórica. Algunos de los debatidores no van más allá de la de algún modo ingenua y quizás incontestable pregunta: ¿Realmente se creen los dirigentes del PCI y del PCE lo que están diciendo en los congresos de sus partidos y, más aún, en sus contactos con los políticos occidentales, con los intelectuales y con los hombres de negocios?

Otros, como Giovanni Sartori, van mucho más allá en la pregunta: "¿Qué pueden hacer los comunistas —incluso asumiendo la honestidad de sus intenciones-, enfrentados con la "realidad de los hechos", con los constreñimientos de los sistemas económicos y sociales, frente a la expectación que han creado entre sus seguidores y, me atrevería a añadir, con las imágenes que sus oponentes tienen de ellos? ${ }^{29}$.

Los Partidos Comunistas de Europa del Sur han abandonado la idea de asaltar el Palacio de Invierno. Después de los resultados desastrosos de los levantamientos guerrilleros en Grecia y España después de la Segunda Guerra Mundial, se han dedicado a la construcción de un partido de masas, mediante un continuo y efectivo esfuerzo, a que sea notada su presencia y a acumular la hegemonía en la sociedad civil a través de una guerra de posiciones (para usar el lenguaje de Gramsci), al mismo tiempo que utilizan las oportunidades electorales de la democracia liberal (incluso la libertad marginal consentida por un régimen liberalizante como el de Franco en las elecciones sindicales y de asociaciones profesionales) y claman firmemente por sus derechos civiles frente a las políticas discriminatorias que limitan su in fluencia. Fue Togliatti, con la «svolta» (vuelta en redondo) de Salerno (el 31 de marzo de 1944), el que inició la política de abandono de la oposición y de colaboración con la monarquía, lo que fue rechazado por otros partidos; más tarde ayudó a la incorporación de los Pactos Laterales con la Iglesia dentro de la Constitución. El historiador comunista Paolo Spriamo liga ese término con el rechazo de la experiencia griega.

Como apuntó Donald Blackmer, tres han sido los problemas que han enfrentado a los partidos comunistas: la organización, la estrategia interna y las relaciones internacionales. Ha caracterizado a las diferentes etapas y políticas de los diversos partidos el peso relativo dado a cada uno de ellos.

En el período inicial, que podía ser descrito mediante la expresión de Guenther Roth: "la integración negativa en las sociedades y en los sistemas políticos" (comparable en algunos aspectos con la postura del movimiento socialista laborista dentro del entorno hostil de la Alemania Imperial), el internacionalismo proletario, con sus ligaduras con el primer Estado socialista y su implicación en los conflictos del movimiento comunista internacional, fue un obstáculo para el logro de otras estrategias. Sólo en los úl-

${ }^{29}$ Giovanni Sartori, Lo scenario del compromesso storico, en "Il PCI dall" opposizione al goberno. E dopo?", en Quaderni di Biblioteca della libertà, 11 (marzo 1978); Giuseppe di Palma, Surviving Without Governing (University of California Press, Berkeley, 1977), pp. 219-286. 
timos años han tratado los partidos de superar dicho obstáculo -haciendo hincapié en el policentrismo, adoptando una actitud más crítica hacia la Unión Soviética (particularmente hacia el estalinismo, aunque también hacia la intervención de Checoslovaquia)-, permitiendo en algunos casos una actitud más liberal hacia los disidentes del Este $y$, finalmente, rechazando la idea de un modelo único de sociedad socialista. Organizativamente, fueron muy cautos los cambios desde una rígida interpretación del centralismo democrático a un nuevo estilo; y la proporción de libertad en los debates internos varía mucho de un partido a otro. La relación con organizaciones colindantes tales como los sindicatos, concebida inicialmente como cadenas de transmisión, también ha variado con el tiempo y de un país a otro; los italianos son los que han llegado más lejos al permitir que el CGLI y otros grupos, tales como la Unión de Mujeres Italianas, tengan más autonomía, en parte para establecer puentes entre las organizaciones comunistas y los grupos católicos para acciones comunes, y en parte, para debilitar los lazos de esas organizaciones con el Partido Demócrata Cristiano. De hecho, algunos de estos desarrollos han creado ciertas tensiones en el partido y pueden muy bien representar problemas cuando el partido entrase en el Gobierno, como han hecho las uniones de los partidos laboristas en el poder.

Los partidos también han variado con respecto a los modos en que aislaban a sus militanes de una sociedad mayor y con respecto al grado por el que constituían una subcultura cerrada, siendo otra vez los italianos, en los últimos años, los más dispuestos a «tirar la toalla» y a abrir sus manos a las fuerzas progresistas fuera del partido, en especial a los católicos; esta política está caracterizada por la dirección de no comunistas en las listas del partido. El PCE, consciente de la importancia del conflicto religioso en España en los años treinta, ha sido partidario particularmente de recibir a sacerdotes bien conocidos y a dirigentes católicos laicos, en un esfuerzo para neutralizar el anticomunismo potencial de la Iglesia. El conocimiento de la importancia de las clases medias - «celti medi»-- por parte de los comunistas italianos y de su papel en la ascensión del fascismo, un aspecto sobre el cual han divergido es la interpretación del Comintern sobre el fascismo, les ha llevado a prestar una atención especial a estas clases, a fin de prevenir los temores y descontentos de aquellos sectores que, de otra forma, podrían beneficiar a los neofascistas. El PCE sigue los pasos italianos al defender constantemente a los pequeños y medianos empresarios y al clasificar a los trabajadores intelectuales y de cuello azul juntos, aunque rechazando el marcado «ouvrièrisme» del PCF y, probablemente, del PCP. Han supuesto serios problemas para los partidos el surgimiento del radicalismo estudiantil y juvenil después de 1968, el nacimiento de nuevos grupúsculos de la izquierda, tanto intelectuales como terroristas, y el nacimiento de nuevas formas de acción dentro de la clase obrera de diversas maneras, según los países y según los diferentes momentos. Algunas veces han enfren- 
tado a los grupos, como hiciera el PCP en una etapa anterior; otras veces, como, por ejemplo, en el golpe de 1975 en Portugal, trataron de incluirlos en una alianza revolucionaria más amplia, conducida por el MFA y apoyada por el partido. En Italia han fluctuado las reacciones, mientras que en España - excepto quizá para algunos de los grupos nacionalistas radicales de la periferia- el PCE ha procurado mantener su distancia y ha evitado cualquier relación con los competidores de la izquierda. El PCI ocupa a este respecto una posición privilegiada si se compara con la del PCE y del PCP, ya que en ningún distrito electoral italiano han excedido los. votos de los partidos situados a su izquierda a los del PCI, lo que no se cumple para el PCE. De hecho, comparados con el 34,4 por 100 de los votos del PCI, los grupos a su izquierda solamente obtuvieron el 1,5 por 100 , mientras que en España el PCE consiguió el 9,3 por 100 de los votos, y la extrema izquierda, el 1,3 por 100. El PCP portugués también tuvo que luchar con varios partidos situados a su izquierda - el 14,6 por 100 contra algo menos del 5 por 100 - El éxito de la candidatura presidencial de Otelo Saraiva de Carvalho, cuyo 27 por 100 de los votos desplazó al candidato comunista Pawo, con el 7 por 100, representó una contrariedad. Es importante resaltar el hecho de que no es sólo el PCE eurocomunista el que se tiene que enfrentar a la competición de los partidos comunistas independientes; incluso el revolucionario PCP, que no es eurocomunista, tiene que afrontar dicha competición. En la Europa de los setenta, la construcción de un partido comunista -en el despertar de la crisis del estalinismo, la rebelión estudiantil, el renovado fermento marxista intelectual, el nacimiento de grupos radicales en los bordes de la Iglesia católica y la división Moscú-Pekín- no es ya lo que fue a finales de los cuarenta, cuando el comunismo ortodoxo era el único contendiente serio de la extrema izquierda.

La dirección moscovita ha mostrado su displicencia con alguna de las tendencias señaladas, pero sólo en Grecia se ha desarrollado una división real entre el Partido Comunista del Exterior (el grupo dominante con el 9,2 por 100 de los votos) y los eurocomunistas (con el 2,3 por 100).

En España, el partido se enfrenta también con la competición de grupos marxista-leninistas, más o menos maoístas, que luchan por la liberación nacional en las regiones periféricas; en algunas de estas zonas -el País Vasco industrial y la subdesarrollada Galicia-, el PCE no tuvo mucho éxito. El carácter multinacional de España ha obligado al partido a presentarse en Cataluña como el Partido Socialista Unificado de Cataluña (PSUC), y existe la vaga impresión de que las posiciones del PCE y del PSUC no son muy iguales.

Los partidos comunistas difieren ampliamente en sus concepciones de cómo conseguir el poder $\mathrm{o}$, al menos, de cómo participar en él. Una alternativa, el Programa Común, ha sido frustrada actualmente por los votantes y rechazada claramente por el PCI al hacer hincapié en la necesidad de una 
mayoría más amplia que el «51 por $100 »$; la idea de una alianza socialistacomunista no ha encontrado tampoco mucho apoyo entre el PCE; y en vista de la reciente historia acerca de las relaciones entre los socialistas y comunistas portugueses tal alianza es más que improbable aun cuando el PCP la desease. En España, la línea del partido ha sido sucesivamente la siguiente: 1) desde 1956, la reconciliación nacional; 2) la creación de amplias alianzas (intentadas primero por la Junta Democrática con éxito limitado; después hubo varias «instancias unitarias» en las que la oposición intentó conseguir la «ruptura» con un gobierno provisional de la oposición e incluso la «ruptura pactada» con una coalición entre el Gobierno existente y la oposición), y 3) el intento actual de un gobierno de concentración democrática. Esto último explica el gran deseo de participar al menos en acuerdos programáricos como los Pactos de la Moncloa de 1977, que fueron propuestos por Suárez para tratar los difíciles problemas económicos durante el período crítico de elaboración de la Constitución. Esto representó para el PCE la oportunidad real de aparecer como un igual con los otros partidos y de tener, indirectamente, algún control sobre la política gubernamental a través de los órganos competentes para el cumplimiento de los pactos. El electoralmente débil PCE, extremadamente consciente de los peligros de una débil mayoría de la izquierda en un país como España, ha aprendido la lección chilena y considera la «vía italiana» mejor que la francesa y la que lo puede salvar del aislamiento del PCP.

El PCP se ha encontrado asimismo en una situación excepcional, una situación revolucionaria o una que parece ofrecer la oportunidad de un cambio revolucionario. Aunque no ha sido de su cosecha, parece ofrecer, en alianza con los oficiales más radicales pero a menudo más inexpertos del MFA, una oportunidad única de utilizar el «poder social» obtenido cuando se produjo el vacío de poder por la caída del régimen de Caetano ${ }^{30}$. Inmediatamente después del 25 de abril de 1974, el PCP procedió cautelosamente a formular sus demandas actuando primariamente como una fuerza para el orden y la moderación e hizo buen uso de las posiciones en el Gobierno que los militares le habían dado, particularmente el Ministerio de Trabajo. La crisis del 28 de septiembre de 1974, en la que participó el partido para aplastar las aspiraciones «gaullistas» de Spinola y que le dio el poder a las facciones más radicales del MFA, le dio la oportunidad de formar una alianza con la izquierda militar y la fortuna de cambiar la estructura económica a través de la reforma agraria y de las nacionalizaciones de los bancos y de gran parte de la industria. El PCP, convencido de su superioridad moral y organizativa, percibió cada vez más que los partidos bur-

${ }^{30}$ Eusebio M. Mujal-León, The PCP and the Portuguese Revolution, en "Problems of Communism", 26 (enero-febrero 1977): 21-41; véase también en la misma publicación Dimitri Kitsikis, Grek Communists and the Karamanlis Government, pp. 42-56. 
gueses eran obsoletos; por eso apoyó los intentos del MFA de establecer lazos directos con el «Pueblo» y con sus iniciativas «apolíticas» y «unitarias». El establecimiento de la Intersindical, en enero de 1975, para el mantenimiento de la unidad del aparato sindical, heredado del sistema corporativo (una esperanza que compartieron las Comisiones Obreras españolas, pero que no pudieron llevar a cabo debido al ordenado proceso de reforma), fue una victoria decisiva. En la primavera de 1975, el PCP optó contra el «electoralismo», pero los radicales del MFA no pudieron evitar las elecciones libres; sin embargo, pudieron imponer un sistema de autoridad dual en el pacto entre los partidos y el MFA.

Las vueltas electorales crearon una nueva situación que condujo en el norte de Portugal a acciones anticomunistas. El PCP apoyó al Primer Ministro Gonçalves después de que los socialistas hubiesen abandonado el Gobierno como protesta por el radicalismo exagerado de la media, pero pronto la unidad del MFA se tornó vacilante, especialmente después de la declaración de los Nueve, bajo la dirección de Melo Antunes. Gonçalves fue desplazado; en el nuevo Gobierno el PCP sólo tuvo una Cartera y los socialistas obtuvieron el poder. A finales de 1975 tocaron techo las tensiones dentro del MFA; los comunistas, en alianza con la izquierda del MFA, se habían convertido en el partido más fuerte; mientras tanto, el partido agitaba para lograr una política más radical. Sin embargo, cuando los grupos ultraizquierdistas dentro y fuera del MFA intentaron su golpe, los comunistas sólo se vieron envueltos a nivel de vecinos y de los comités de trabajadores; la dirección prefirió ver cuál sería la corriente de los acontecimientos.

Después del 25 de noviembre de 1975, los nuevos dirigentes del Ejército se opusieron a que continuase el dominio militar, pasando el poder a los civiles y revisándose el pacto entre el MFA y los partidos políticos. Desde que el PCP abandonó su postura agresiva, de orientación izquierdista, ha tratado de defender su poderosa posición en los sindicatos y en la zona rural del sur-centro de Portugal, así como de establecer puentes, particularmente a nivel superficial, con los socialistas; pero su poderosa presencia y su presión hicieron difícil para la minoría socialista en el Gobierno el acomodarse a las demandas de los partidos a su derecha, por lo que, consecuentemente, se produja la inestabilidad del Gabinete. Se podría debatir sobre si la línea tomada por el PCP durante aquellos años críticos fue el resultado de las características sociológicas de un partido que siempre había operado en la ilegalidad, ocultamente, o la respuesta a una situación histórica única.

Se podría hacer la misma pregunta respecto a la política bien conocida - y diametralmente opuesta- del PCI y a la política, todavía naciente, del PCE.

Desde 1976, cuando el PCI obtuvo un sin precedentes 34,4 por 100 de los votos y 228 de los 629 escaños, ha sido ampliamente debatido el tema 
de cómo se podría gobernar sin los comunistas y sobre si el PCI entraría en el Gobierno y con qué consecuencias ${ }^{31}$. Los éxitos del PCI -al incrementar el 27,2 por 100 de los votos obtenidos en 1972- han señalado para muchos el final del modelo de alternancia periférica con la hegemonía de la DC, el agotamiento de la política de clientelismo, hecha posible gracias al milagro económico; el impacto de las nuevas expresiones de protesta civil y la creciente expresión de una revolución civil, cuya terminación fue prevenida largamente por la $\mathrm{DC}^{32}$. La crisis de la sociedad italiana suscitó en el PCI - un partido con deseos de gobernar - la pregunta de cómo acceder al poder. Berlinguer, conocedor de la experiencia chilena y temeroso de lo que él llamó «la división del Estado» - los riesgos del mandato de una mayoría con el 51 por 100-, excluyó el modelo de la alternancia y propuso la fórmula del «compromesso storico» —una gran coalición- no como recurso temporal, sino como la vía italiana al socialismo.

Los analistas difieren en el significado que debería darse a una coalición gubernamental formada por la DC y el PCI, con o sin la participación de partidos menores. Algunos de ellos ven en dicha coalición una continuación del tradicional modelo italiano del transformismo; otros, como Luigi Graziano ${ }^{33}$, la ven como un nuevo tipo de política consociacional, mientras que Giovanni Sartori, partiendo de la concepción de que el PCI no es un partido como los otros, se centra, sobre las bases de un análisis situacional, en las consecuencias a larga escala. Los argumentos son complejos y sólo podemos esbozar un esquema somero de las conclusiones derivadas, dejando de lado la pregunta de si el PCI entraría en el Gobierno y cuándo. La contestación a dicha pregunta dependerá de la respuesta que dé el electorado a los partidos y de las expectativas que ofrezca tal coalición, de la intensidad de la crisis del orden público, económico y social, y también del deseo del PCI de entrar en el Gobierno con todos los riesgos que conlleva para el futuro del partido.

Se podría argumentar el que han existido grandes coaliciones, como la del CDU y del SPD en Alemania, que han contribuido a la transición a la

${ }^{31}$ Howard R. Penniman (ed.), Italy at the Polls. The Parliamentary Elections of 1976 (American Enterprise Institute for Policy Research, Washington D. C., 1977); Arturo Parisi y Gianfranco Pasquino (eds.), Continuità e mutamento electorale in Italia: le elezioni del 20 Giugno 1976 e il sistema politico italiano (II Mulino, Bolonia, 1977).

32 Sobre la crisis de la democracia italiana, véanse Fabio Luca Cavazza y Stephen R. Graubard (eds.), Il caso italiano (Aldo Garzanti, Milán, 1974); Peter Lange, The PCI and Possible Outcomes of Italy's Crisis, en Luigi Graziano y Sidney Tarrow (eđs.), "L'Italia tra crisis e transizione" (Einaudi, Turín, 1978); Giuseppe di Palma, Political Syncretism in Italy: Historical Coalition Strategies and the Present Crisis (Inst. de Estudios Internacionales, Policy Papers in International Affairs, Berkeley, 1978).

"Luigi Graziano, Compromesso storico e democrazia consociativa: verso una "nuova democrazia"?, informe presentado en la Conferencia sobre la Europa mediterránea, IPSA, Atenas, mayo de 1978. 
alternancia; pero los datos indican que todavía existe una parte significativa del electorado italiano que todavía sospecha del PCI como para permitirle el gobernar solo, que la comunidad internacional podría responder negativamente y que los inversores podrían reaccionar negativamente desestabilizando la economía italiana. El PCI concibe, por tanto, la coalición como un acuerdo más o menos permanente. También destacan los observadores qué partidos comunistas han participado, desde la guerra, en gobiernos occidentales y que todavía permanecen en los gabinetes de Islandia y Finlandia, sin que por eso se hayan producido cambios políticos importantes. En contra de este punto de vista se argumenta el que no todas las coaliciones son iguales, y que no es la mismo tener al Partido Comunista finlandés representado en el Gabinete (con un 20 por 100 aproximado de votos) que al PCI apoyado por un tercio del electorado. Además, en Finlandia, los partidos no comunistas pueden formar gobiernos relativamente estables y efectivos sin necesidad del apoyo y participación comunista, lo que, aparentemente, no es el caso de Italia.

En los últimos años, desde el trabajo de Arend Lijphart ${ }^{34}$, el concepto de la democracia consociativa ha sido utilizado para analizar situaciones multipartidistas en las que los conflictos potencialmente divisorios entre las subculturas lingüísticas, étnicas, religiosas e ideológicas están sostenidos mediante estrategias políticas más que por mandato mayoritario, como: las coaliciones gubernamentales, la proporcionalización de la vida pública, la negociación entre las élites obligadas por sus seguidores y demás. Resultaba tentador el utilizar el modelo consociativo para interpretar, como un camino para superar el bloqueo mutuo en la toma de decisiones, el futuro del «compromesso storico», para mitigar las sospechas y los temores entre los compañeros antagonistas y para estabilizar, frente a las amenazas de los extremos, la democracia. La solución está en compartir el poder - como lo ha sido en muchas sociedades fraccionadas de forma consociativa- en vez de elegir el gobernar mediante un partido central único, demasiado débil para mandar efectivamente y teniendo que escoger la alternativa imposible de llevar a cabo cambios radicales en la sociedad a través de la dictadura del proletariado. Los que defienden esta posibilidad, generalmente también están a favor de dicha solución, aunque son conscientes de algunas de las diferencias fundamentales que existen entre el consociativismo de las democracias europeas menores y el de la Italia actual. En principio, las subculturas fraccionadas no son expansivas. Su apoyo suele estar congelado y los acuerdos tienden a evitar manejos aún más expansivos de cualquiera de los compañeros - una política de la que son buenos ejemplos los pactos de los colegios-. Desde luego, el PCI, con su noción gramsciana de la hege-

${ }^{34}$ Arend Lijphart, Democracy in Plural Societies. A Comparative Exploration (Yale University Press, New Haven, Conn., 1977). 
monía y su dinamismo interno, es inherentemente expansivo; la centralidad del proletariado, la negación de la legitimidad al capitalismo, el compromiso de lograr la victoria decisiva del socialismo, la concepción de «marchar a través de las instituciones» y las tácticas de la «guerra de posiciones» no parecen ser compatibles con el modelo consociativo. Realmente existe prisa por compartir el poder político con la DC, pero al mismo tiempo es retenida la noción gramsciana de hegemonía para el "poder social». El objetivo de consociativismo no es el consolidar, en mayor o menor grado, un statu quo y hacer posibles las reformas, sino el lograr cambios fundamentales pensando concretamente en el socialismo.

La pregunta se centra en cómo tal gobierno con los dos partidos dominantes compartiendo alrededor del 75 por 100 de los votos trabajaría en la actualidad. ¿Puede ser ocupado al mismo tiempo y de forma duradera el núcleo de la coalición por dos partidos de fuerza aproximadamente igual y con claras ambiciones de gobernar? Sartori resalta que sería una coalición desigual, dadas las posiciones muy diferentes que ocupan en la sociedad la DC y el PCI. La DC, como partido patronal que es, obtiene mucho de su poder de los lazos clientelísticos, y los clientes tienden a irse allá donde está el poder. Por otro lado, la $\mathrm{DC}$ ha perdido mucha de la influencia que tenía sobre grupos de interés, en concreto con sus sindicatos, mientras que las organizaciones de la esfera comunista han cobrado fuerza. La DC no puede, como sí podría el PCI, movilizar en la calle en una situación de crisis. La división inevitable del patronazgo y de la influencia del gran sector público, unido a los esfuerzos del PCI y a su papel preeminente en la vida intelectual, harían, desde el punto de vista de Sartori, la alianza de los compañeros antagónicos cada vez más desigual, incluso aunque el PCI no asumiera ningún Ministerio importante o no violara ninguna de las reglas del juego democrático, a lo que podríamos añadir que, tal y como es jugado en Italia, sin estar bien definidas las fronteras entre la sociedad civil y la política, entre la economía y la política y entre la burocracia y la partidocracia.

En términos de Sartori, esta «diarchia polarizzata», y según la versión de Graziano, un nuevo tipo de democracia consociativa, se enfrentaría a una serie de problemas que, generalmente, se dejan sin analizar. Es perfectamente concebible el que, para legitimar esta fórmula política - tanto internamente como internacionalmente sobre todo-, la coalición debería proceder cautelosamente, a fin de asegurar el apoyo de la comunidad mundial de negocios y para neutralizar los temores de los inversores italianos, así como realizar un serio esfuerzo para relanzar la economía, moderando especialmente las demandas de los sindicatos a los que estaría sujeta. De hecho, muchos conservadores ven en tal coalición el único medio de romper el estancamiento actual, al oponer el universalismo al clientelismo, y la racionalidad y la productividad contra las intrusiones parasitarias. Sin embargo, 
Sartori no deja el análisis en este estadio, sino que llama la atención sobre los serios problemas que el PCI eventualmente pudiese encontrar. Los grupos que hubiesen apoyado en el primer estadio las políticas racionales empezarían, más adelante, a preguntar por los frutos de la victoria, por todas las reformas sociales, tan a menudo propuestas y que fueron propuestas por el partido. Por su parte, la DC no puede olvidar el defender los intereses de sus constituyentes. El resultado sería una inflación creciente. Con la creciente autonomía de los sindicatos frente a los partidos, con el conocimiento creciente de que los saldos finales del poder son limitados (y el aumento resultante de las tensiones y de los debates internos de los partidos) y la necesidad de mantener la lealtad electoral de grupos sociales heterogéneos, un gobierno tal tendría que enfrentarse a problemas quizá aún más serios que los actuales. Suponiendo incluso la lealtad de la masa del partido y de los intereses ligados a él, habría un gran número de verdaderos revolucionarios que, habiéndose tomado en serio los textos sagrados y las esperanzas, ejercerían presión. Probablemente, algunos de ellos se tornarían hacia una forma u otra de la guerra de guerrillas. Todo el mundo esperaría que el ahora partido dominante en el Gobierno y en la sociedad resolviera los problemas acumulados durante décadas, y las expectativas se acomodarían mediante las afirmaciones continuas acerca de que, de hecho, el partido sería capaz de resolverlos, y todo el mundo esperaría que el partido, enfrentado por la violencia creada por reducidos grupos de extremistas, la suprimiese. En este punto, el tema suscitado por Sartori es el siguiente: ¿será entonces el partido, dentro del esquema de la democracia que invocó cuando estaba en la oposición, capaz de hacerlo, con lo que podríamos llamar sus componentes libertarios? Bajo tales circunstancias, ¿sería capaz de gobernar con un método de gobierno que no es el suyo? $\mathrm{O}$, forzado por las circunstancias (incluso en contra de su voluntad), ¿volvería a otro método, bienvenido probablemente, por grandes sectores de la sociedad deseosos de orden y estabilidad, más quizá que de libertad? Queremos hacer constar que las especulaciones acerca del futuro de Italia no necesitan cuestionar la sinceridad de los compromisos con las reglas democráticas del juego, con el pluralismo y con las elecciones; pero tienen que estar basadas en un análisis sobre los cambios dinámicos de la situación -económicos, sociales e internacionales-, y éstos no pueden ser previstos actualmente por los protagonistas. Todavía las situaciones futuras tienen sus raíces en el pasado que conocemos. Sería un primer experimento de consecuencias desconocidas, y sería decisivo, no sólo para Italia. Dado el compromiso del PCE con la «via italiana», su éxito o su fracaso tendrían seguramente un impacto en España. De hecho, creemos que la perspectiva de un gobierno PSOE-UCD en la actualidad, «servata distantia», posee de forma atenuada los mismos problemas que hemos descrito. 
España: De una Nación-Estado centralista a un Estado multinacional regionalizado

Desde nuestro punto de vista, el problema más complejo al que se enfrenta actualmente la democracia española, el cual no tiene paralelo en Italia, Portugal o Grecia, es la transformación de un Estado centralizado a uno regionalizado. Las fuertes tendencias autonomistas del País Vasco, Cataluña, las Islas Canarias y, en menor medida, de Valencia, Galicia y cada vez más las de Andalucía, ya han empezado a crear problemas complejos y difíciles ${ }^{35}$. Si añadimos que en el País Vasco, especialmente en la provincia de Guipúzcoa, existe un fuerte sentimiento nacionalista y separatista, que se manifiesta a través de las acciones minoritarias de un movimiento revolucionario terrorista - la rama militar de Euskadi Ta Askatasuna (ETA - y a través de un partido nacionalista a la izquierda del PNV, el Euskadiko Ezkerra (EE) (que en Guipúzcoa fue capaz de obtener el 9,5 por 100 de los votos), la complejidad del problema parece ser obvia.

España es una Nación-Estado para la inmensa mayoría de los españoles. Grandes sectores de la población del País Vasco y de Cataluña sienten que la identificación con una nacionalidad periférica no es incompatible. con la lealtad a España, lo que es especialmente cierto en el caso de Cataluña. Pero todavía una pequeña minoría de catalanes y un número significativo de vascos no se identifican con España, sino con una Nación que puede aspirar al Estado protector. El problema es complicado, porque estas dos regiones industrialmente avanzadas, con sus altos niveles de vida, han atraído a un gran número de inmigrantes cuya identidad nacional es la española. En el País Vasco estos recién llegados son plenamente aceptados sólo a medias, incluso aunque lograsen asimilarse, lo cual es improbable debido a la dificultad del idioma vasco. Entre esos inmigrantes el sentimiento centralista es tan fuerte como lo es el sentimiento separatista entre los que hablan el vasco. Más aún, no existe una mayoría para cualquier solución particular, incluso entre los nacidos vascos, ya que están divididos en sus aspiraciones, las cuales dependen del idioma que utilicen y de la provincia de residencia. El conflicto del País Vasco, que ya ha alcanzado elevadas cotas de violencia

"Suan J. Linz, Early State-Building and Late Peripheral Nationalisms against the State, en S. N. Eisenstadt and Stein Rokkans (eds.), "Building States and Nations: Models, Analyses and Data across Three Worlds", vol. 2 (Sage, Beverly Hills, Calif., 1973), pp. 32-112; Stanley G. Payne, Basque Nationalism (University of Nevada, Reno, Nev. 1975); Alberto Pérez Calvo, Los partidos políticos en el País Vasco (Tucar, Madrid, 1977); Luis C. Núñez, Clases sociales en Euskadi (Thertoa, San Sebastián, 1977); Salustiano del Campo, Manuel Navarro y J. Félix Tezanos, La cuestión regional española (Edicusa, Madrid, 1977), y José Jiménez Blanco, Manuel García Ferrando, Eduardo López Aranguren y Miguel Beltrán Villalva, La conciencia regional en España (Centro de Investigaciones Sociológicas, Madrid, 1977). 
y que ha causado brutales asesinatos, es en sentido amplio un conflicto entre vascos y no entre éstos y el Gobierno central.

Las complejas uniones de clase y de las políticas nacionalistas dividen entre los nativos y los inmigrantes las muy diversas posturas de la población de las diferentes provincias - todos son factores que complican cualquier solución-. Nadie puede hablar en nombre de todo el pueblo vasco, al menos dentro de las fronteras de lo que los nacionalistas vascos consideran su casa; incluso en Cataluña, donde el consenso sobre las aspiraciones autonomistas es mucho más elevado, la clase política divide a la sociedad. Esta falta de consenso interno, junto con otră serie de factores, hacen muy dudosa la solución de un modelo consociativo según el esquema de Arend Lijphart. La heterogeneidad interna de estas dos sociedades industrializadas, la asimilación dentro del idioma y cultura castellana de la parte llana de la población nativa, la heterogeneidad resultante de las divisiones de clase y, en menor grado, la religiosidad, hacen poco probable el que una dirección regionalista con apoyo mayoritario capaz de hablar en nombre de la región pueda alcanzar y conseguir un acuerdo consociativo con el Gobierno central. Obviamente, han existido y existen tendencias en Cataluña en ese sentido; las negociaciones y los acuerdos entre el Presidente Suárez y Tarradellas, el Presidente de la Generalitat, que regresó después de años en el exilio, encajan en el modelo de Lijphart. Pero aunque la autoridad de Tarradellas como representante de Cataluña no se cuestiona, no existe nadie que pueda representar su papel en el País Vasco.

Todos los otros factores descritos en el tema del consociativismo -el pequeño país, amenazado desde el exterior, que cuenta con proporciones relativamente semejantes de elementos componentes, con una dirección bien establecida que puede negociar y que tiene autoridad para unir a su junta electoral, con la ausencia de elementos homogéneos constantes y en estrecho contacto que crean fricciones, y con tradiciones e instituciones que canalizan las aspiraciones de los diferentes sectores- están ausentes en el caso del País Vasco y escasean en Cataluña.

Ultimamente he tratado estos problemas por todas partes. Examinando los últimos datos y las vueltas electorales en el País Vasco, sus provincias y Navarra (la cual reclaman los vascos), existe una mayor evidencia acerca de lo agudo del problema de los nacionalismos periféricos contra el Estado $y$ del multilingüismo en una sociedad con un idioma como el castellano, dominante en el mundo.

Debemos añadir a estos dos problemas tradicionales del Estado español el incierto clima de opinión dentro de las Islas Canarias. Las Islas, que están sujetas a las presiones de las actividades terroristas animadas desde fuera, se sienten muy lejos de la región metropolitana y se han visto fuertemente afectadas económica y psicológicamente por la descolonización del Sahara, justo enfrente de ellas. También se sienten olvidadas por una Administra- 
ción central muy lejana. Aunque este clima de opinión todavía no se ha reflejado en las elecciones políticas - los partidos más amplios, la UCD y, en menor medida, el PSOE obtuvieron una porción abrumadora de votos-, se ha mostrado en las últimas elecciones sindicales y adquiere una importancia especial debido a la posición estratégica de las Islas y a las pretensiones africanas, a pesar del hecho de que toda la población es blanca y habla castellano, excepto en algunas colonias extranjeras, especialmente de mercaderes indios. Para contradecir en parte el argumento de que la autonomía concedida recientemente a las regiones periféricas industrialmente ricas es un privilegio injusto, el partido del Gobierno ha favorecido la regionalización de otras partes de España. En algunos casos, los partidos de la izquier$\mathrm{da}$, con la esperanza de controlar a los gobiernos regionales, han hecho suyas las demandas anticentralistas. En todas partes de España existen agravios fácilmente explotables contra la burocracia central. Por ejemplo, el subdesarrollo de algunas regiones, como Andalucía y Galicia, pueden ser fácilmente atribuidos a la negligencia gubernamental, a la extracción de capital, a través del sistema bancario, para la inversión en las regiones industriales avanzadas y al control exterior de sus recursos naturales y de las empresas industriales. En este contexto, la demagogia retórica ha creado y está creando unas elevadas expectativas de que con la autonomía regional se podrían resolver los problemas del subdesarrollo, especialmente en Andalucía. La verdad es algo más compleja, y es muy improbable que los gobiernos regionales, sin contar con una infraestructura administrativa, puedan rápidamente resolver los problemas económicos y sociales tradicionales, que últimamente se han visto acentuados por la crisis económica general y, sobre todo en Andalucía, por el consiguiente desempleo. Falta todavía por ver cómo van a ser las relaciones entre los gobiernos central y regionales, entre las regiones ricas y pobres $\mathrm{y}$ entre las coaliciones gubernamentales de diferente composición en el centro y en las regiones. Probablemente se desarrollen tensiones, siendo las expectativas defraudadas, la incapacidad de los gobiernos regionales de responder a las presiones que probablemente ellos mismos generaron, entre otros, los problemas más complejos a los que se va a tener que enfrentar la nueva democracia española.

\section{Conclusión}

Las sociedades sur europeas se encuentran ellas mismas en una difícil coyuntura. En la última década y media han sufrido los mayores cambios económicos y sociales de su historia más reciente. Quizá, por primera vez durante siglos, han experimentado sus poblaciones la esperanza de una vida mejor. Excepto en Italia, han vivido bajo regímenes autoritarios que no les proporcionó un canal para la participación en la vida política, que recortó 
o pisoteó los derechos humanos y que resultaron anacrónicos en la nueva Europa democrática. Por diferentes razones, y a través de procesos bastante diversos, esos regímenes dieron paso a democracias nuevas en un tiempo de crisis económica, lo que las ha afectado profundamente. La transición hacia la democracia ha coincidido también con un momento de crisis ideológica y de ambigüedades, no dejándoles modelos claros a seguir o a rechazar. La crítica marxista del modelo social-demócrata o neoliberal, propio de las democracias estables de la Europa Occidental; el rechazo del modelo soviético por parte de los comunistas; la crisis de la Iglesia católica y, con ella, de la alternativa política de la Democracia Cristiana, han creado una incertidumbre en las élites de estos países acerca de dónde y cómo seguir en el futuro. Han surgido sueños nuevos, a veces confusos, dentro del esquema democrático, sobre las diferentes soluciones para sus problemas.

Para esas élites, la democracia burguesa formal, esperada durante tanto tiempo, parece insuficiente ahora que está llegando; son receptivas a las críticas a las que está sujeta en los países más avanzados económica, política y socialmente. Los nuevos regímenes sufren el bache adicional de haber nacido en un momento en el que no pueden, dentro de los límites de sus economías, llevar a cabo políticas progresistas que identificarían a la población con ellos; como resultado tienen que enfrentarse a una crisis de legitimidad. El pasado ha dejado una herencia de temores: memorias de guerras civiles, de intervenciones militares y de dictaduras; los intentos revolucionarios o pseudorrevolucionarios frustrados pesan fuertemente sobre los dirigentes y les conduce hacia la búsqueda de un consenso más que hacia la alternancia de gobiernos que pudiese incorporar en el proceso político a aquéllos en los extremos. La legitimidad limitada de algunos de los participantes ante los ojos de grandes sectores de la población, el veto potencial de grupos clave y su potencial para el chantaje, han creado problemas periódicos de legitimidad. En algunos casos éstos se resuelven perpetuando o extendiendo coaliciones exclusivas en el poder y englobando intereses heterogéneos -evitando, por tanto, la expectativa de la alternancia en el Gobierno-. Muchos de los protagonistas temen que dicha alternancia pudiese dividir a los países o provocar la oposición motivada de sectores poderosos y significativos de la sociedad —específicamente de los militares, de los trabajadores organizados o de los agitadores de las calles. Sus extremados sistemas multipartidistas les enfrentan con los peligros de la polarización, fragmentación o del inmovilismo-, sino de todos juntos simultáneamente. En el caso de España, tenemos que añadir la seria amenaza de los nacionalismos periféricos, y más específicamente del separatismo vasco, contra la unidad de la Nación.

Los sistemas políticos, de cara a estos problemas de institucionalización y de lucha democrática pacífica por el poder, están enfrentados a elecciones difíciles, impuestas por el estado de desarrollo económico y político de sus 
naciones y por la situación internacional. Sus países ya han dejado de ser sociedades agrarias subdesarrolladas; están, en gran parte, industrializadas y urbanizadas, compartiendo, por tanto, muchos de los problemas de las naciones más ricas, pero con menos recursos para resolverlos. Han alcanzado un nivel de desarrollo que ha creado expectativas nuevas y más altas. Están demasiado cerca de los países avanzados de Europa como para permanecer indiferentes a los cambios que llevan implícitas las etapas más avanzadas del estado del bienestar y a los derechos que garantiza. Pero sus economías necesitan capital para la continua modernización que les permita alcanzar un mayor nivel de complejidad tecnológica y ser competitivos dentro del esquema europeo, especialmende desde que otros países están ahora en la etapa de despegue que ocuparon hace una o dos décadas y están deseando alcanzarles pronto y ser sus competidores. La desigualdad entre el norte y el sur de Europa es una fuente de tensiones que, al menos psicológicamente, no son muy diferentes de aquellas entre el Tercer Mundo y los países industrializados. Objetivamente, sin embargo, la Europa del Sur está muy por delante del Tercer Mundo, incluyendo a la mayor parte de América Latina. Pero como su atención está centrada en Europa como marco de referencia, a menudo se ignora su posición relativamente privilegiada, y las respuestas de los intelectuales y políticos del Tercer Mundo algunas veces encuentran eco en el Mediterráneo. El pasado ha dejado una herencia de desigualdad social considerable, la que, en algunos casos, ha exacerbado el desarrollo económico, aun cuando la mayoría de los sur europeos vivan mejor hoy que hace dos décadas. Esa desigualdad que constantemente se hace visible contribuye a deslegitimar el orden económico, social y político naciente. La importante presencia de partidos comunistas y de extrema izquierda, así como el potencial de radicalización de algunos partidos socialistas, son un reflejo y una causa de esas ilegitimidades del orden social. El hecho de que la mayoría del cambio económico haya tenido lugar durante el período autoritario, que era en sí mismo ilegítimo, ha contribuido al cuestionamiento fundamental del orden social.

¿Serán capaces estas sociedades de realizar la transición hacia formas más avanzadas de producción, de una utilización más efectiva de sus recursos y de una mayor integración en el mercado mundial de los países avanzados? ¿Serán capaces de llevar a cabo profundas transformaciones tecnológicas y científicas y al mismo tiempo enfrentarse a una crisis de integración política, así como a fuertes presiones en la redistribución y, en algunos casos, a una crisis de la identidad nacional?

Es casi imposible responder a estas preguntas. Para terminar, podemos citar una conclusión escrita por Giuseppe di Palma acerca de estos mismos cuatro países: «Las transiciones de régimen y las mayores crisis coalicionales están acompañadas por una deflación del poder y por una aceleración y acumulación de sucesos, a menudo impredecibles; la oportunidad y el riesgo 
desempeñan un papel más allá de lo que un Estado firme permite. Y cuando los sucesos se convierten en aleatorios, cuando las élites políticas y los expertos tienen que confiar en una información limitada y distorsionada, cuando el cálculo arriesgado no es siempre racional y universal, resulta entonces muy difícil el predecir en qué dirección se están moviendo los regímenes y las coaliciones, a menos que estemos contra los acontecimientos» ${ }^{36}$.

La transición hacia la democracia, después de años de gobierno autoritario, ha creado nuevas esperanzas, y los conflictos del pasado han originado un deseo de cambio democrático pacífico y de libertad entre muchos de los dirigentes políticos, y más aún entre amplios sectores de la población. El reciente y rápido desarrollo económico, a pesar de las desigualdades en su distribución, ha creado la posibilidad de continuar el progreso. Corresponde a las élites de todos los partidos y a los dirigentes de todas las instituciones el fijar realmente las posibilidades del cambio dentro de las constreñidas condiciones del pasado y de los años setenta.

36 Giuseppe di Palma, "Left, right, right, left or center? Sobre la legitimación de los partidos y de las coaliciones en el sur de Europa", Conferencia sobre la Europa mediterránea, IPSA, Atenas, mayo de 1978. Su análisis converge y complementa en muchos aspectos con los nuestros. 